\title{
Industry 4.0-Driven Development of Optimization Algorithms: A Systematic Overview
}

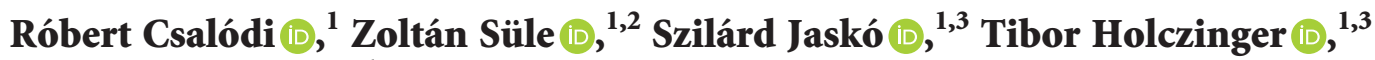 \\ and János Abonyi (iD ${ }^{1}$ \\ ${ }^{1}$ MTA-PE Lendület Complex Systems Monitoring Research Group, University of Pannonia, Veszprém H-8200, Hungary \\ ${ }^{2}$ Department of Computer Science and Systems Technology, University of Pannonia, Veszprém H-8200, Hungary \\ ${ }^{3}$ Department of Applied Informatics, University of Pannonia, Nagykanizsa Campus, Nagykanizsa H-8800, Hungary
}

Correspondence should be addressed to János Abonyi; janos@abonyilab.com

Received 17 December 2020; Accepted 30 January 2021; Published 13 February 2021

Academic Editor: Renke Han

Copyright (c) 2021 Róbert Csalódi et al. This is an open access article distributed under the Creative Commons Attribution License, which permits unrestricted use, distribution, and reproduction in any medium, provided the original work is properly cited.

The Fourth Industrial Revolution means the digital transformation of production systems. Cyber-physical systems allow for the horizontal and vertical integration of these production systems as well as the exploitation of the benefits via optimization tools. This article reviews the impact of Industry 4.0 solutions concerning optimization tasks and optimization algorithms, in addition to the identification of the new R\&D directions driven by new application options. The basic organizing principle of this overview of the literature is to explore the requirements of optimization tasks, which are needed to perform horizontal and vertical integration. This systematic review presents content from 900 articles on Industry 4.0 and optimization as well as 388 articles on Industry 4.0 and scheduling. It is our hope that this work can serve as a starting point for researchers and developers in the field.

\section{Introduction}

The Fourth Industrial Revolution aims to increase the efficiency of production systems and exploit the advantages of digital transformation. Digital transformation is built on cyber-physical systems, which are complex objects that are created by connecting different types of elements (IT, mechanical, etc.) and can interact with physical entities [1]. They facilitate monitoring as well as interactions with other components and can be adapted to production processes [2]. Cyber-physical systems are one of the key enabling technologies of Industry 4.0. Cyber-physical systems are able to effectively support the optimization of production processes, which helps future requirements to be met [3].

The biggest challenges and opportunities caused by the Fourth Industrial Revolution are introduced in Figure 1. It is quite visible that the basis of competitiveness in this new production model is personalised production, which requires the enhanced flexibility and complexity of production processes driven by growing product variety. Obviously, this greater complexity requires solutions to more and more challenging optimization issues. These issues are listed in Table 1.

As the development of Industry 4.0 solutions is related to optimization tasks, this paper aims to overview the optimization tasks, algorithms, and future development direction of these systems according to the Industry 4.0 concept.

General review papers about cyber-physical systems as an enabling technology of Industry 4.0 can be found [4]. Although an enormous number of information sources can be used, no review papers have been written about the optimization solutions of Industry 4.0. The goal, inspired by this shortcoming, is to publish a review paper targeting the topic of optimization in Industry 4.0, which is suitable as a starting point for researchers and developers in the field. The need for this kind of focused analysis has been proven by the publication of many targeted review articles over recent years, e.g., on topics such as the influence of Industry 4.0 on energy consumption [5], the enhancement of fault diagnosis by machine learning methods [6], the combination of opportunities of Industry 4.0 and lean philosophy [7], and the handling of cybersecurity risks [8]. The concept of this work 


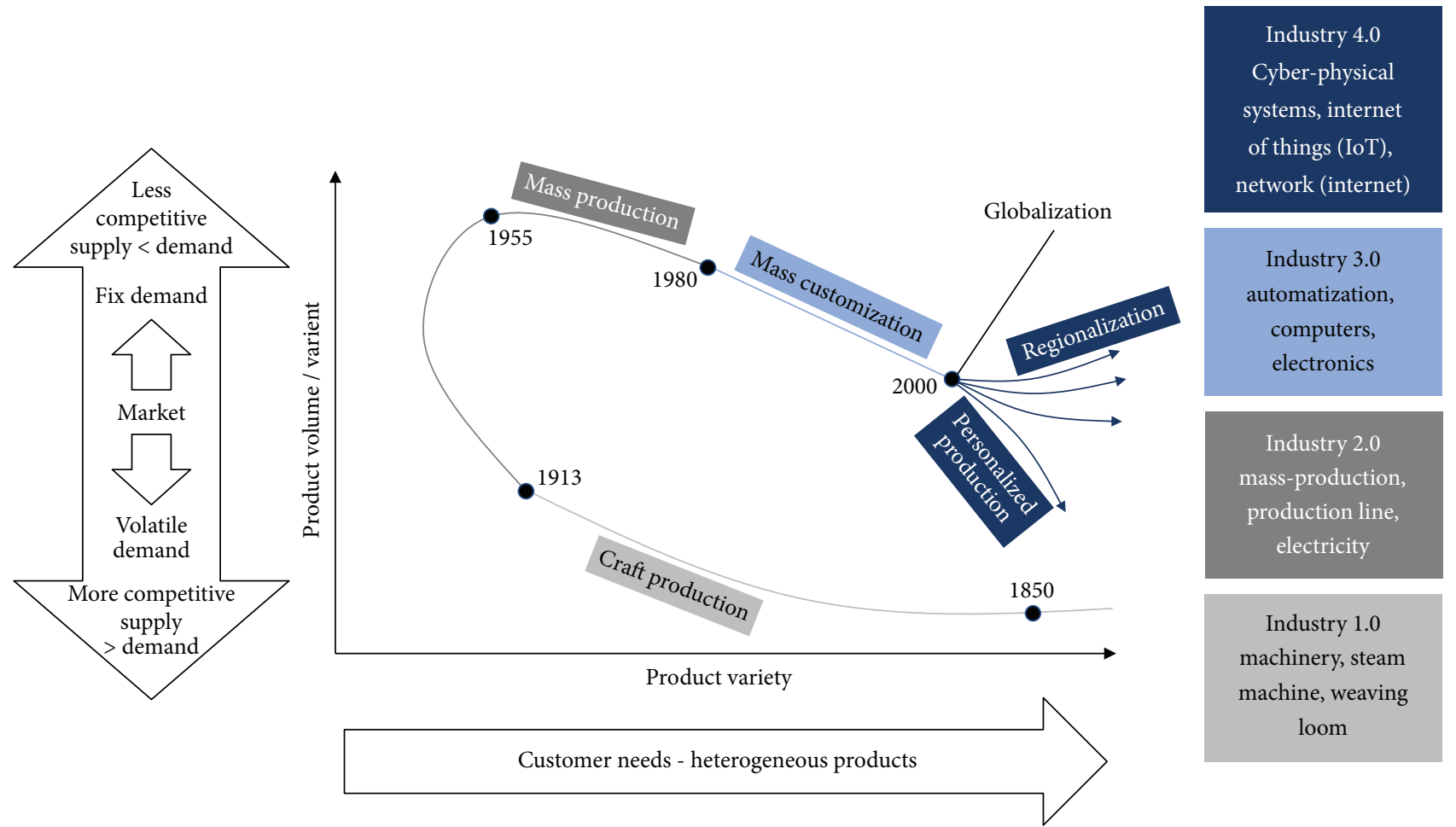

Figure 1: The evolution of industry and the change in drivers.

TABle 1: Optimization issues in Industry 4.0 systems.

\begin{tabular}{|c|c|c|}
\hline Objectives & Restrictions & Manufacturing operations \\
\hline $\begin{array}{l}\text { Determine the size of a job (batch, } \\
\text { run) }\end{array}$ & Inventory & - Highly complex \\
\hline Assign it to a production line & $\begin{array}{l}\text { Availability of resources (labor, } \\
\text { machines) }\end{array}$ & - Rely on manual scheduling/use complex spreadsheets \\
\hline Sequence jobs on each line & $\begin{array}{l}\text { - Changeovers/cleanings/planned } \\
\text { maintenance }\end{array}$ & - Need to improve on-time delivery \\
\hline $\begin{array}{l}\checkmark \text { Maximize throughput/quantity } \\
\text { produced }\end{array}$ & - Unplanned downtime & - Experience inefficient changeovers/setups \\
\hline $\begin{array}{l}\checkmark \text { Minimize operating cost/ } \\
\text { changeovers }\end{array}$ & - Operator availability & $\begin{array}{c}\text { - Have multiple products sharing common resources } \\
\text { (labor, infrastructure) }\end{array}$ \\
\hline$\checkmark$ Maximize o & $\begin{array}{c}\text { Emergency/expedited customer } \\
\text { orders }\end{array}$ & $\begin{array}{c}\text { - Production costs are a large proportion of the cost of } \\
\text { goods sold }\end{array}$ \\
\hline $\begin{array}{l}\checkmark \text { Minimize total time to complete } \\
\text { production }\end{array}$ & $\begin{array}{l}\text { - Maintenance requirements } \\
\text { Delivery promises }\end{array}$ & $\begin{array}{l}\text { - Want to increase production without additional capex } \\
\text { - Need to reduce operating costs, product losses/waste }\end{array}$ \\
\hline
\end{tabular}

is based on the requirement to develop Industry 4.0 solutions to systematize the publications related to optimization tasks.

This systematic review is based on an examination of the literature available from Scopus, following the PRISMA-P (Preferred Reporting Items for Systematic reviews and Meta-Analysis Protocols) [9]. The PRISMA-P workflow consists of a 17 -item checklist intended to facilitate the preparation and reporting of a robust protocol for systematic reviews. The information sources were last fully queried in October 2020 with the following keywords:

(1) (Industry 4.0 AND (optimization OR optimisation))

(2) (Industry 4.0 AND scheduling)
The studied papers were published between 2013 and 2021 and consist of 900 articles on optimization and Industry 4.0 as well as 388 articles on scheduling and Industry 4.0 topics. The complexity of optimization tasks and the approaches to solve them are highly varied. Deviations are caused as a consequence of horizontal and vertical integration. The key contributions and structure of this paper are as follows:

(1) The requirements arising from horizontal and vertical integration that determine the development of optimization algorithms are introduced in Section 2.1.

(2) The characteristics of Industry 4.0 solutions are summarized and the requirements for optimization tasks are presented in Section 2.2. 
(3) The quantitative analysis of the $900+388$ articles related to optimization and scheduling, respectively, is performed based on the aspects explored, the typical applications determined, and the relationship system of the solutions described by network analysis in Section 3.

(4) Typical optimization tasks are formalized, their complexity and metric system are determined, and the impact of changes on the development of these algorithms inducted by the analysis of Industry 4.0driven solutions is analyzed in Section 4.1.

(5) The characteristics of optimization tasks and the requirements of Industry 4.0 solutions are presented in Section 4.2.

(6) Future research areas are identified based on current trends in Section 4.3.

\section{Horizontal and Vertical Integration of Industry 4.0 and the Related Requirements}

The purpose of this chapter is to describe the principles of developing Industry 4.0 solutions before presenting optimization tasks. It aims to identify the driving forces that may determine the development of optimization algorithms. Vertical integration and horizontal integration as the main defining factors are discussed in Section 2.1, while features and further requirements of Industry 4.0 are introduced in Section 2.2.

2.1. Horizontal and Vertical Integration of Industry 4.0. The complexity and nature of optimization problems are primarily varied due to horizontal and vertical integration established by Industry 4.0. The purpose of this section is to present these trends and features. Optimization tasks are executed in various fields of Industry 4.0. Improving the efficiency of the Production and Operations Management $(\mathrm{POM})$ is also a cardinal task to increase performance. Two forms of integration approaches are designed, namely, the horizontal and vertical integration. Both types, which are discussed in the following sections, have special requirements and aim to support the POM.

\subsubsection{Requirements of Vertical Integration. Vertical inte-} gration focuses on the internal integration of manufacturing enterprises and aims to convert data, events, and information from the real world into the digital world, and vice versa [10]. The model is described by the ISA-95 standard [11] and was established to support the development of POM information systems. This standard defines five levels of manufacturing tasks [12], and its goal is to make the connection between the lowest (production execution) and highest (business planning and logistics) stages by integration. The levels and descriptions of ISA-95 can be seen in Figure 2, and various optimization and decision-making exercises are also introduced. The levels define different types of optimization and decision tasks [13]. It can be observed, for example, at the third and fourth levels that operation needs to be optimized by analyzing the adequacy of regulatory and control processes. Schedules and production plans can be qualified by the indicators of appropriateness in order to set suitable input parameters. Planning, scheduling, and optimization are inputs of each other, forming a set of closed loops, and therefore depend on each other. In an integrated solution, it is advisable to solve these optimization tasks simultaneously, in an integrated way.

In summary, the requirements of vertical integration are as follows:

(1) As planning, scheduling, and operation tasks are dependent on each other, these tasks should be solved simultaneously and integrated

(2) More and more information should be extracted to provide informative feedback to support real-time optimization

\subsubsection{Requirements of Horizontal Integration. Horizontal} integration aims to bring together all the supplier and customer networks, thereby supporting supply chain management. Therefore, information on the production processes is acquired and analyzed in real time in an intelligent production network system by connecting with the Global Enterprise Cloud [14]. This cloud involves the individual entities in the partnership and optimization should cover the entire supply chain within and between organizations simultaneously. This network is called a connected supply chain, and an example of its construction is presented in Figure 3. A connected supply chain will lead to an efficient operation and reduces the costs dramatically but increases complexity.

The most relevant example of horizontal integration is described by collaborative manufacturing management (CMM) [16]. CMM is the practice of organizing and managing manufacturing enterprises. It focuses on the collaboration between partners, Business Process Management (BPM) services, and real-time strategic business management tools. It connects internal business and manufacturing processes as well as synchronizes them with external business processes. It focuses primarily on facilitating in addition to managing business processes and secondarily on support systems [17]. Through collaboration skills, capacities and capabilities are offered to companies by sharing resources and essential information [18]. Actually, CMM is not a new concept. The necessity of this type of integration has already been recognized, but, at the time, could not be properly developed. It was hard to find a suitable partnership to develop a nonhierarchical network, but Industry 4.0 tools seem to support the CMM structure [19]. A network needs to be organized that integrates the various customer-supplier and design-support aspects most effectively in order to increase the efficiency of the business and production [20]. This can be framed by establishing appropriate internal and external links between partners and within the company. The relationship between these requirements is considered in Figure 4. Equipment connectivity aims to join production systems; therefore, all the 


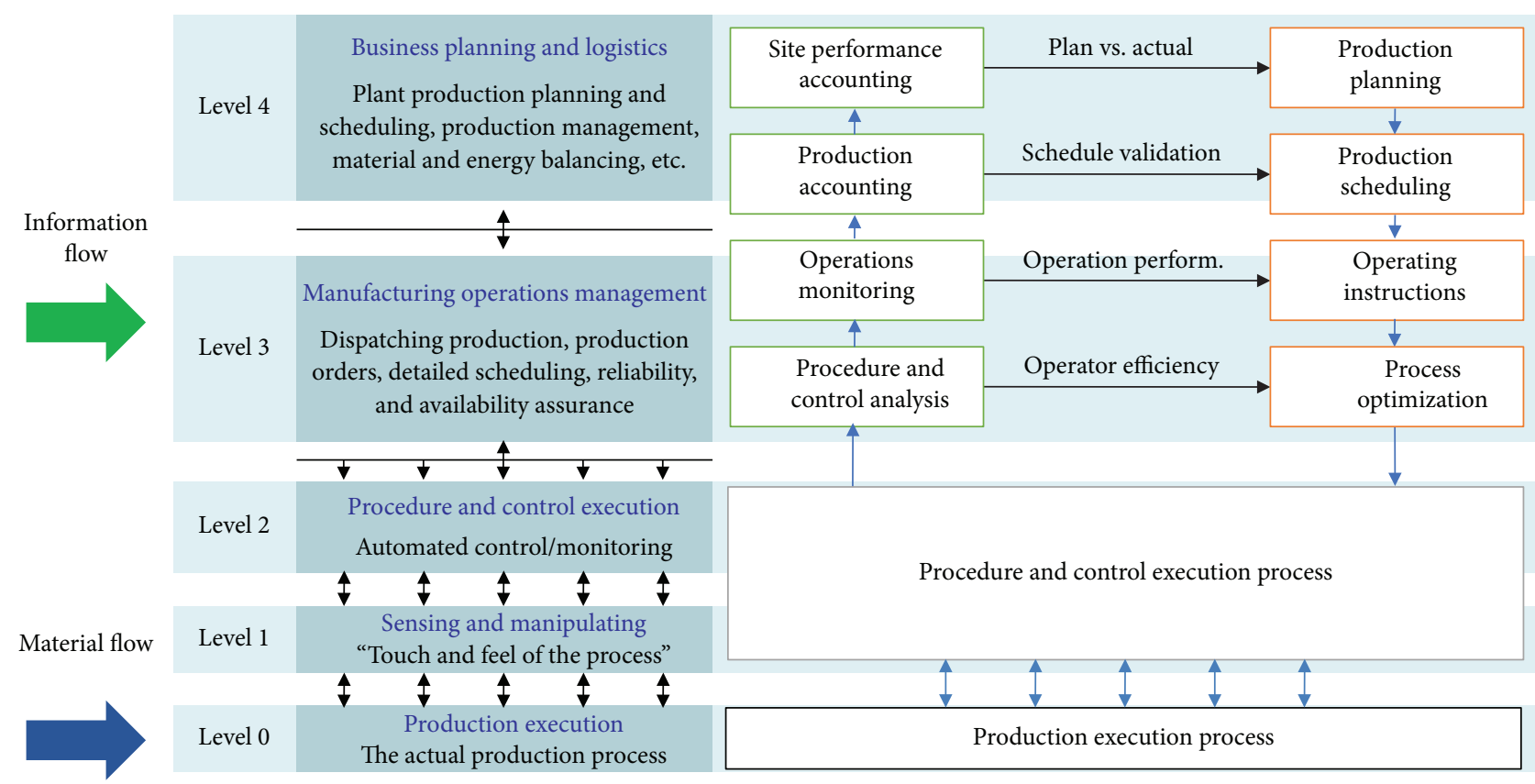

FIgURE 2: The structure of the ISA-95 standard for constructing vertical integration. It defines 5 levels for the internal hierarchy of manufacturing enterprises. Its purpose is to bridge the highest and lowest stage. A description can be found on the left-hand side of the figure, while optimization and decision-making exercises are also introduced on the right-hand side.

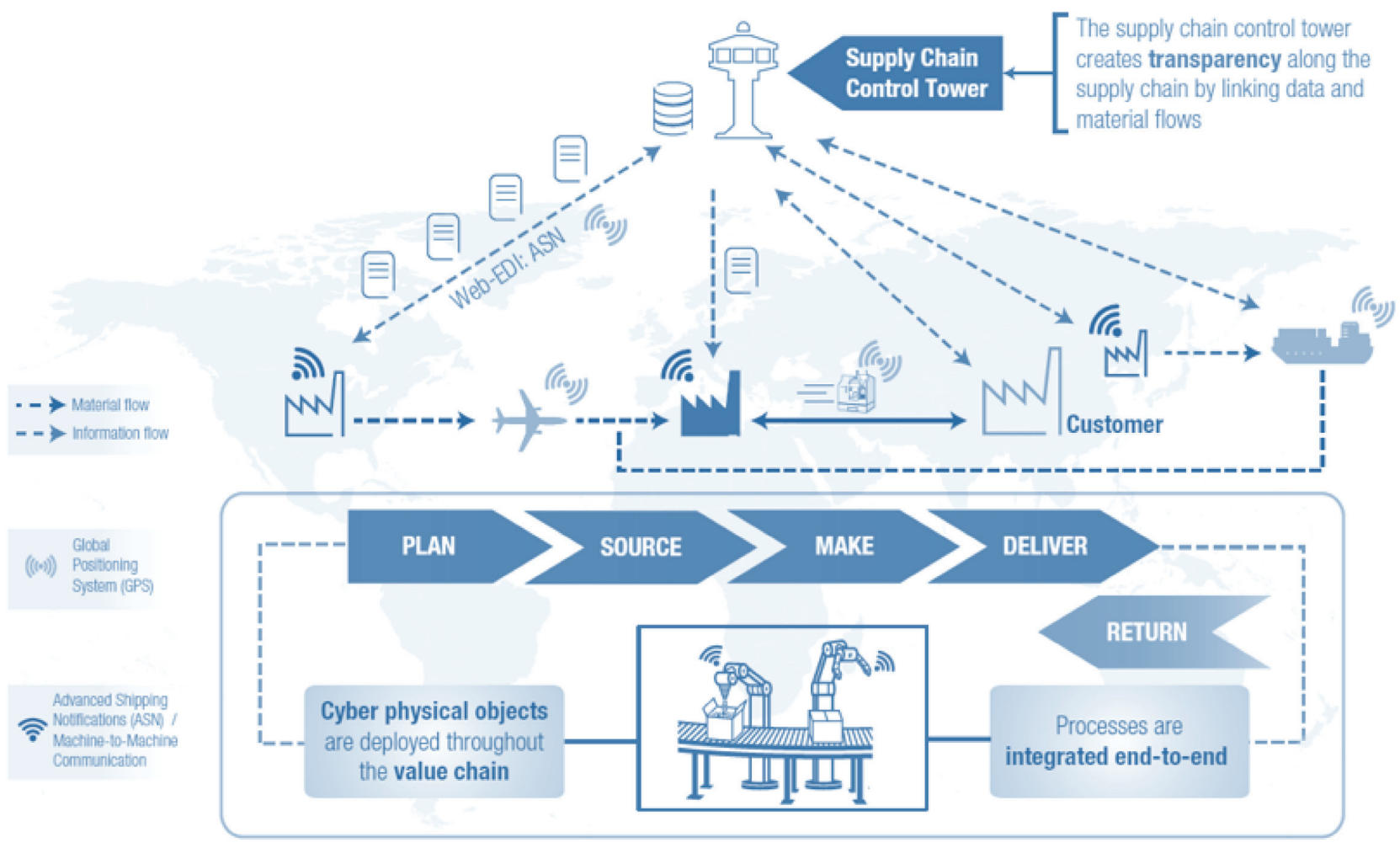

Figure 3: The structure of horizontal integration. Components of the partnership can be found all over the world. An organized supply chain is formed for tracking the life cycle of the product. Planning, sourcing, manufacturing, and delivery processes operate simultaneously. Cyber-physical systems and their connectivity via GPS or Internet enable full communication in order to set the optimal parameters [15].

information is available to the elements of the network. Visibility requires the aggregation of data about the operation to define performance indicators in order to qualify the system appropriately.
The efficient operation of a CMM structure requires complex tasks to be solved. The available studies are about hypernetwork-based model scheduling to improve the utilization and efficiency of manufacturing [21]; the 


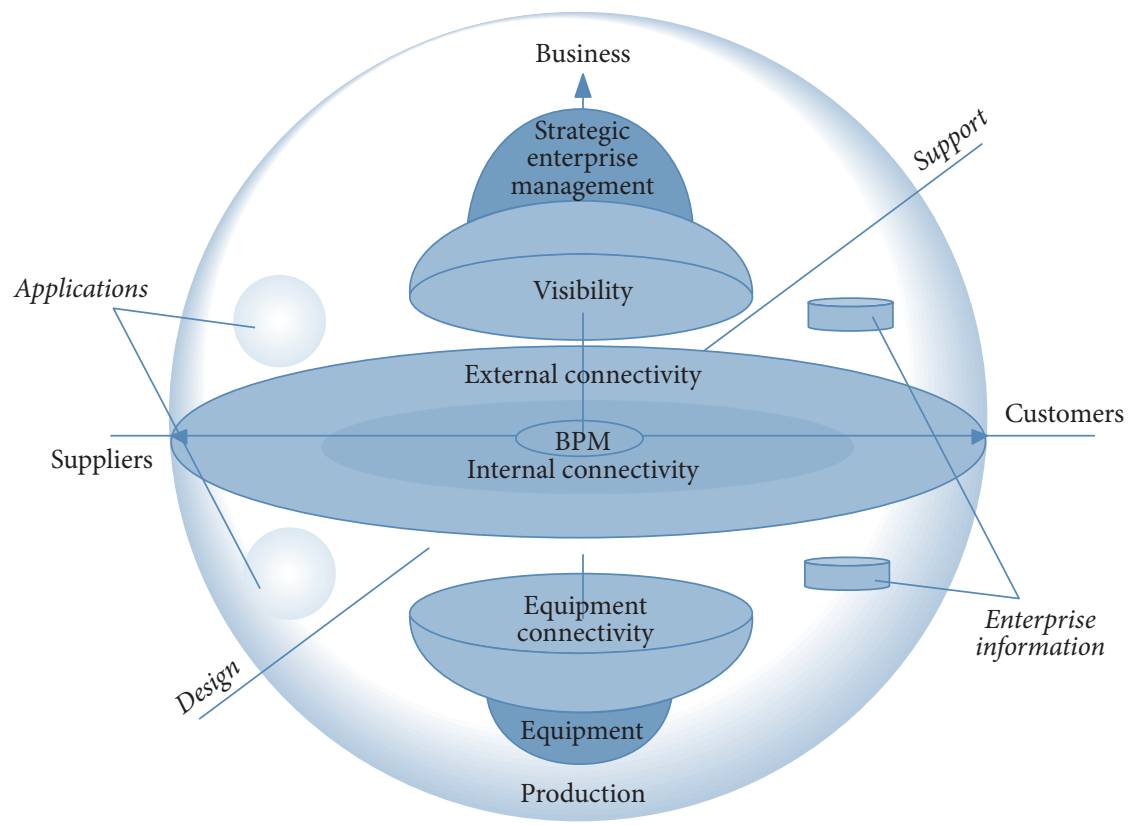

FIgURE 4: The framework of the collaborative infrastructure. Collaboration must be established between units within the organization as well as between partners and customers outside the organization. Access to equipment and the visibility of strategic management are important at all levels of the structure [17].

architecture of human-robot systems including control, safety, and interface components [22]; security system frameworks to ensure the protection of data interaction during manufacturing [23]; and the exploration of approaches moving towards a cloud manufacturing ecosystem [24].

In summary, the requirements of horizontal integration are as follows:

(1) A need for tools that can optimize the total supply chain

(2) A need for tools that can simultaneously optimize different tasks such as scheduling, maintenance, production, and logistics

2.2. Features of Industry 4.0 Solutions: Further Requirements for the Development of Optimization Algorithms. In order to explore additional requirements, in this section, the features and further requirements of Industry 4.0 are presented. Industry 4.0 has clear, well-defined design principles that can refine its image. The requirements are defined based on the following four tenets [25]: interconnection, decentralized decision, information transparency, and technical assistance. These four design principles led to rapid development; moreover, the aforementioned principles were insufficient to fully characterize the aims and trends that have emerged. New properties have appeared that could provide a more detailed characterization of the design [26]. This phenomenon occurred again, and a more detailed description was necessary. Additional design considerations were identified as follows $[27,28]$. The principles of the solutions and their relation to optimization are summarized in Table 2; moreover, examples are also given.
Horizontal and vertical integration can facilitate further optimization opportunities such as the Lean Six Sigma Tools [29]. They help to update the classical Manufacturing Execution System (MES) applications to monolithic Manufacturing Operations Management (MOM) [30], which forms the basis of up-to-the-mark cyber-physical systems (CPS) [31]. Horizontal and vertical integration can be supported by digital twin solutions. A publication reported the application of a digital twin, which provides service-based and real-time enabled infrastructure for vertical and horizontal integration [32]. Another paper introduced a viewpoint-oriented approach to identify functional components that facilitate decision-making within a manufacturing ecosystem [33].

In summary, Industry 4.0 is a more complex and connected concept than previous ones. It consists of many aspects that sometimes conflict with each other in practice. It only remains workable if the integration (vertical and horizontal) is an essential part of its implementation. Partly because of integration and partly because of the many data sources, a large amount of data are generated every second that need to be stored, processed, and aggregated. That is why Big Data is one of the key services in Industry 4.0. Decentralization is important in this concept, but the many services of Industry 4.0, e.g., data storage and decisionmaking, raise the following question: Is a decentralized, centralized, or mixed strategy the best choice in the given situation? The place/layer where decisions are made depends partly on feasibility and partly on the aforementioned strategy. This level of complexity is hardly or completely unmanageable. Therefore, the following question arises: Is the goal to identify the optimal operation or to search and maintain efficient and reliable operation? If the problem can 
be broken down into smaller parts, they can already be simulated, and a multilevel simulation can be used for several overlapping subtasks. In addition to the traditional tasks, the simulations should also provide an answer to how the industrial process will be sustainable and fit into the circular economy (CE) because this viewpoint will become increasingly stronger in everyday life, so the companies have to account for it.

The name column in Table 2 shows the requirements and characteristics of Industry 4.0 except optimization. A description is given for every property that presents more information about it. Their effects on optimization are accumulated for each element based on our experience. If the column contains more " + " signs, the expected effect of that element on optimization will be greater. Every row shows an example of the relationship between optimization, Industry 4.0 , and the given row in the given column. It can be clearly seen that our expectation is the following: the greatest effect is exerted by real-time capability, but corporate social responsibility, sustainability, flexibility, smart factories, virtualization, decentralization, modularity, interoperability, and smart products also affect it significantly. Furthermore, it is also worth noting that all requirements and characteristics of Industry 4.0 have an effect in this context. They are quantitatively analyzed in the following sections to determine whether our expectations are true or not.

\section{Quantitative Analysis of the Related Publications}

In this section, a quantitative analysis is presented concerning the available literature based on keywords, namely, Industry 4.0 and optimization. Such an analysis is very appropriate because the structure and topicality of the examined papers can be revealed. The publications over time show an ascending trend, and it can be observed that $80 \%$ of the papers were published between 2018 and 2020 (until October). The distribution of publications is shown in Figure 5.

The articles were published in many different scientific journals. It can be concluded that plenty of journals welcome papers on the topic of Industry 4.0. The found studies were published by more than 400 different journals or conference events. 25 journals that published the most studies are summarized in Table 3, and their distribution over the years is also included.

The study of keywords and their connections is also a practical aspect of the analysis. Keywords hide profitable information about the frameworks, methods, applications, or enabling technologies of the examined topic. The keywords that occur most frequently are gathered to show the importance weight of individual Industry 4.0 items, and their numbers of occurrences are visualized in Figure 6.

The linkage between Industry 4.0 and other keywords can be illustrated well separately using clustering algorithms. The connectivity of the keywords was obtained by VOSviewer software. The method gathers the keywords that occur together. Its hyperparameter is the minimum number of occurrences which was set at three. The results are illustrated in Figure 7.

The derived framework of keywords is separated according to fields of application, namely, wireless sensor network, smart grid, availability, and agriculture. An algorithm part is also present as well as genetic and evolutionary algorithms in addition to particle swarm optimization. Block scheduling also plays an important role and it is connected to the supply chain, modelling as well as cloud and lean manufacturing. Energy optimization is also an essential element of the network and is related to digital factories, sustainable manufacturing, and multiobjective optimization. The Internet of Things as the number one enabling technology of Industry 4.0 is also often referred to as a keyword and linked to cyber-physical systems, machine learning, modelling, and smart factories.

The integration and features of Industry 4.0 were introduced in Section 2. Their enabling and characterizing items can be found in the keywords. Vertical integration is characterized by the unification of company manufacturing levels for efficient production. Typical keywords appear, namely, Internet of Things, cyber-physical systems, smart manufacturing, energy optimization, control, monitoring, scheduling, productivity, and process optimization. Horizontal integration typically aims to create supply chain networks. As a result, the life cycle of the product can be traced. Specific keywords consist of supply chain, sustainability, energy optimization, business process optimization, cloud manufacturing, resource efficiency, and smart manufacturing networks.

A remarkably infrequent keyword is the operator, whose role is diminishing as a consequence of the development of Industry 4.0 .

As has been seen previously in Section 2, Table 2 includes our expectations about the effects of the elements of Industry 4.0 on optimization. The data uncovered during the research are shown in Figure 8, which confirm the previous assumptions. Currently, real-time capability is the hottest topic in this context. A large number of works also deal with corporate social responsibility, flexibility, and smart factories. However, it is important to note that active research is underway in all the remaining areas.

The key message of the figure is that multiple goals usually need to be met simultaneously in the case of Industry 4.0 , and the role of corporate social responsibility has continually increased. It is important to note that more and more goals can be managed in parallel as technology advances, which is increasingly opening the door to the wider usability of multiobjective optimizations.

These principles can be further discussed based on the related Industry 4.0 approaches. The concepts determined are associated with the given requirements. The concepts of the given requirements are defined, and to this end, connected keywords are included in parentheses in Table 4 based on Figure 7. The purpose of this table is to show which concepts should be used to achieve the different requirements and how it is possible to find cross-conceptions based on these keywords. For example, if autonomy should be achieved, one of the key concepts is machine 
TABLE 2: Effect of the requirements and characteristics of Industry 4.0 on optimization.

\begin{tabular}{|c|c|c|c|}
\hline Name & Description & $\begin{array}{c}\text { Effect on } \\
\text { optimization }\end{array}$ & Examples \\
\hline Vertical integration & $\begin{array}{l}\text { It integrates all logical layers within an organization, starting from the } \\
\text { production floor to the business layer. }\end{array}$ & + & {$[34,35]$} \\
\hline Horizontal integration & $\begin{array}{l}\text { It integrates data transfer across multiple production facilities or even } \\
\text { the entire supply chain. A horizontally integrated company } \\
\text { concentrates on the kinds of activities that are closely related to its } \\
\text { competencies; moreover, it builds partnerships to support the end-to- } \\
\text { end value chain. }\end{array}$ & + & {$[36,37]$} \\
\hline End-to-end engineering & $\begin{array}{l}\text { It describes a process that takes a system or service from beginning to } \\
\text { end and delivers a complete functional solution, usually without } \\
\text { needing to obtain anything from a third party. }\end{array}$ & + & {$[38,39]$} \\
\hline Smart factory & $\begin{array}{l}\text { It is a highly digitized and connected production facility that relies on } \\
\text { smart manufacturing where the final goal is to organize the production } \\
\text { facilities and logistics systems without human intervention. }\end{array}$ & ++++ & {$[40,41]$} \\
\hline Product personalization & $\begin{array}{c}\text { It is a process of delivering customized goods and services to the } \\
\text { customers as per their needs and desires. }\end{array}$ & ++ & {$[42]$} \\
\hline Virtualization & $\begin{array}{l}\text { It is the creation of a virtual-rather than actual-version of something, } \\
\text { such as an operating system or production process. }\end{array}$ & ++++ & {$[43,44]$} \\
\hline Decentralization & $\begin{array}{l}\text { It is a structure, where the activities of an organization, particularly } \\
\text { those regarding planning and decision-making, are distributed or } \\
\text { delegated away from a centralized infrastructure. }\end{array}$ & +++ & {$[45,46]$} \\
\hline Flexibility & $\begin{array}{l}\text { It is the ability to react to changes within a predetermined scope of } \\
\text { requirements (corridor of action) time- and cost-effectively. }\end{array}$ & +++++ & {$[47,48]$} \\
\hline $\begin{array}{l}\text { Corporate social responsibility } \\
\text { (CSR) and sustainability }\end{array}$ & $\begin{array}{l}\text { It is a self-regulating business model that helps a company to be socially } \\
\text { accountable to itself, its stakeholders, and the public. Sustainability } \\
\text { focuses on meeting the needs of the present without compromising the } \\
\text { ability of future generations to meet their needs. }\end{array}$ & ++++++ & {$[49,50]$} \\
\hline Real-time capability & $\begin{array}{l}\text { It is the ability of a device or system to collect and analyze data as well as } \\
\text { to respond instantaneously to a command, event, or input. }\end{array}$ & ++++++++ & {$[51,52]$} \\
\hline Modularity & $\begin{array}{l}\text { It determines which independent and interlocking subsystems build the } \\
\text { system based on their functionality. }\end{array}$ & +++ & {$[53,54]$} \\
\hline Interoperability & $\begin{array}{c}\text { It is the ability of systems to exchange information of unambiguous } \\
\text { meaning. }\end{array}$ & +++ & {$[55,56]$} \\
\hline Smart product & $\begin{array}{l}\text { It is a data processing object, which has several interactive functions. It } \\
\text { combines the physical and software interfaces; moreover, the usage of a } \\
\text { smart product is interactive as well as requires also some cognitive work } \\
\text { by the user. }\end{array}$ & +++ & {$[57,58]$} \\
\hline Autonomy & $\begin{array}{l}\text { It is the capacity to make an informed, uncoerced decision. } \\
\text { Autonomous organizations, institutions, machines, or systems are } \\
\text { independent or self-governing. }\end{array}$ & ++ & {$[59,60]$} \\
\hline Agility & $\begin{array}{c}\text { It is defined as the ability of firms to sense environmental change and } \\
\text { respond readily. }\end{array}$ & ++ & {$[61,62]$} \\
\hline Service orientation & $\begin{array}{l}\text { It offers a service (of cyber-physical systems, humans, or smart } \\
\text { factories) via the Internet of Services. }\end{array}$ & ++ & {$[63,64]$} \\
\hline
\end{tabular}

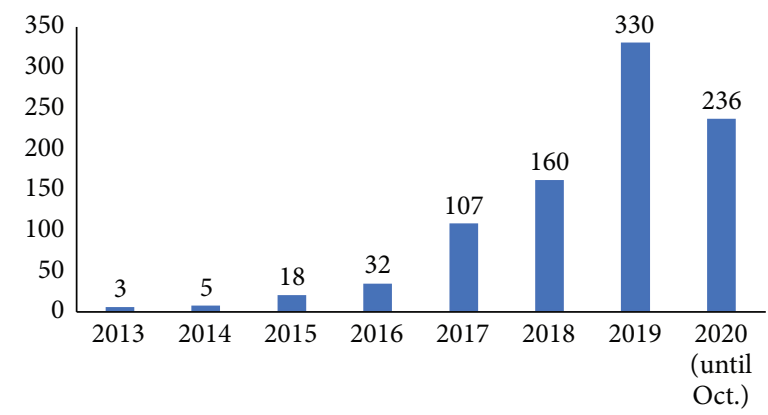

FIGURE 5: Number of publications per year. 
TABLE 3: Articles by journal and period. The 25 most frequently publishing journals can be considered as well as the number of published papers each year.

\begin{tabular}{|c|c|c|c|c|c|c|c|c|c|}
\hline \multirow{2}{*}{ Journal } & \multicolumn{8}{|c|}{ Articles published per year } & \multirow{2}{*}{ Tota } \\
\hline & 2013 & 2014 & 2015 & 2016 & 2017 & 2018 & 2019 & $2020^{*}$ & \\
\hline Procedia Manufacturing & 0 & 0 & 1 & 0 & 11 & 6 & 11 & 9 & 38 \\
\hline Procedia Computer Science & 0 & 0 & 0 & 0 & 0 & 0 & 17 & 15 & 32 \\
\hline IOP Conference Series: Materials Science and Engineering & 0 & 0 & 0 & 0 & 1 & 2 & 23 & 4 & 30 \\
\hline IFAC-PapersOnLine & 0 & 0 & 1 & 5 & 2 & 3 & 19 & 0 & 30 \\
\hline Procedia CIRP & 0 & 0 & 0 & 1 & 6 & 4 & 8 & 5 & 24 \\
\hline Advances in Intelligent Systems and Computing & 0 & 0 & 0 & 0 & 1 & 7 & 6 & 9 & 23 \\
\hline IEEE Access & 0 & 0 & 0 & 1 & 6 & 0 & 5 & 5 & 17 \\
\hline IFIP Advances in Information and Communication Technology & 1 & 0 & 0 & 0 & 5 & 1 & 4 & 5 & 16 \\
\hline IEEE ICA-ACCA 2018-IEEE International Conference on Automation/23rd & & & & & & & & & \\
\hline $\begin{array}{l}\text { Congress of the Chilean Association of Automatic Control: Towards an } \\
\text { Industry 4.0-Proceedings }\end{array}$ & 0 & 0 & 0 & 0 & 0 & 0 & 15 & 0 & 15 \\
\hline $\begin{array}{l}\text { Lecture Notes in Computer Science (including subseries Lecture Notes in } \\
\text { Artificial Intelligence and Lecture Notes in Bioinformatics) }\end{array}$ & 0 & 0 & 1 & 1 & 0 & 2 & 5 & 3 & 12 \\
\hline Journal of Physics: Conference Series & 0 & 0 & 0 & 0 & 0 & 1 & 8 & 2 & 11 \\
\hline Applied Sciences (Switzerland) & 0 & 0 & 0 & 0 & 0 & 0 & 4 & 7 & 11 \\
\hline Proceedings of SPIE-The International Society for Optical Engineering & 0 & 0 & 0 & 0 & 1 & 1 & 5 & 2 & 9 \\
\hline Lecture Notes in Mechanical Engineering & 0 & 0 & 0 & 0 & 0 & 2 & 0 & 7 & 9 \\
\hline International Journal of Advanced Manufacturing Technology & 0 & 0 & 0 & 0 & 0 & 4 & 2 & 3 & 9 \\
\hline ZWF Zeitschrift fuer Wirtschaftlichen Fabrikbetrieb & 1 & 1 & 3 & 1 & 2 & 0 & 1 & 0 & 9 \\
\hline $\begin{array}{l}\text { Proceedings of the International Conference on Industrial Engineering and } \\
\text { Operations Management }\end{array}$ & 0 & 0 & 0 & 1 & 1 & 3 & 2 & 1 & 8 \\
\hline Sustainability (Switzerland) & 0 & 0 & 0 & 0 & 0 & 1 & 2 & 5 & 8 \\
\hline Sensors (Switzerland) & 0 & 0 & 0 & 0 & 0 & 0 & 1 & 6 & 7 \\
\hline Communications in Computer and Information Science & 0 & 0 & 0 & 0 & 2 & 0 & 3 & 1 & 6 \\
\hline $\begin{array}{l}\text { IEEE International Conference on Industrial Engineering and Engineering } \\
\text { Management }\end{array}$ & 0 & 0 & 0 & 0 & 0 & 2 & 4 & 0 & 6 \\
\hline Computer Aided Chemical Engineering & 0 & 0 & 0 & 1 & 2 & 2 & 1 & 0 & 6 \\
\hline Proceedings of the Summer School Francesco Turco & 0 & 0 & 0 & 1 & 2 & 2 & 1 & 0 & 6 \\
\hline $\begin{array}{l}2019 \text { IEEE International Workshop on Metrology for Industry } 4.0 \text { and IoT, } \\
\text { MetroInd } 4.0 \text { and IoT 2019-Proceedings }\end{array}$ & 0 & 0 & 0 & 0 & 0 & 0 & 6 & 0 & 6 \\
\hline International Journal of Production Research & 0 & 0 & 0 & 1 & 0 & 1 & 1 & 3 & 6 \\
\hline
\end{tabular}

*Until October.

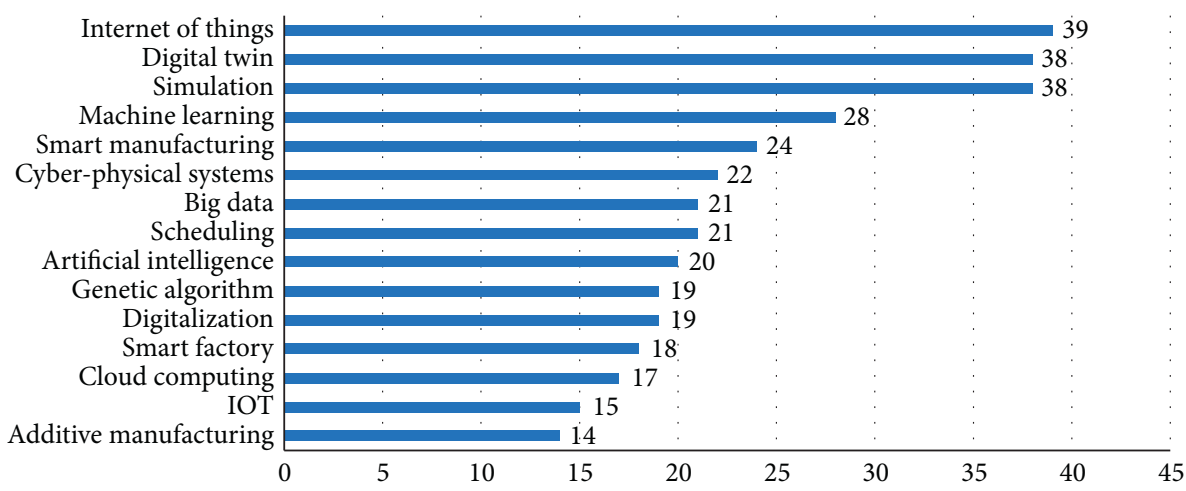

Figure 6: Frequency of the most commonly occurring keywords.

learning. Efficient learning is greatly supported by the Internet of Things as well as artificial intelligence. Data analysis, process optimization, and predictive maintenance can also be applied.

900 relevant papers can be found in the literature from 2013 to the present concerning the fields of Industry 4.0 and optimization. Table 5 shows the frequencies of occurrence of the major optimization areas in Industry 4.0, where the optimization tasks and their descriptions as well as some illustrative examples are given.

Industry 4.0 is a global and versatile topic, as revealed by the keyword analysis. The distribution of publications over the years has shown that much research aims to examine this subject. Plenty of journals are also available for reporting new solutions. 


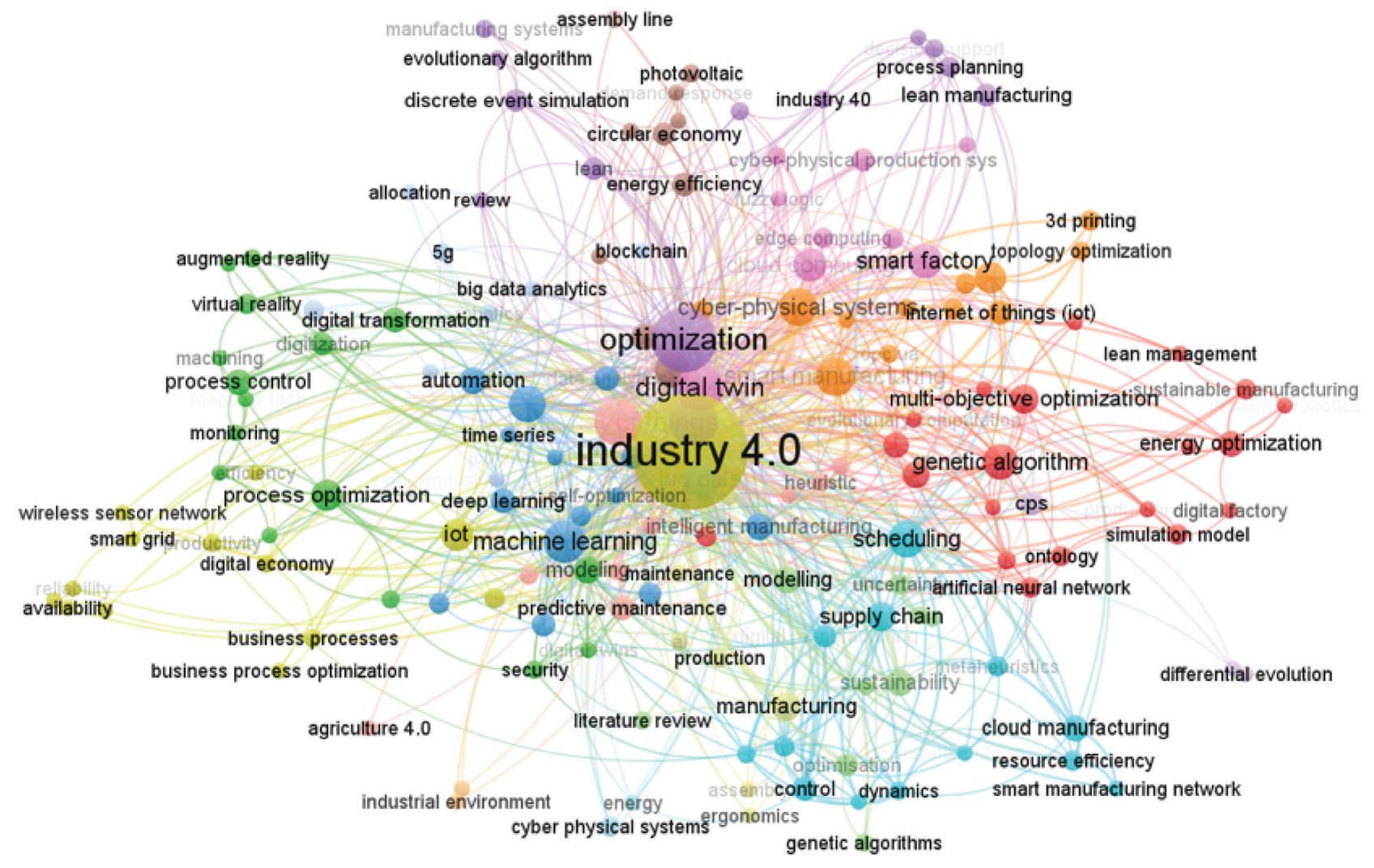

FIGURE 7: The linkage of keywords.

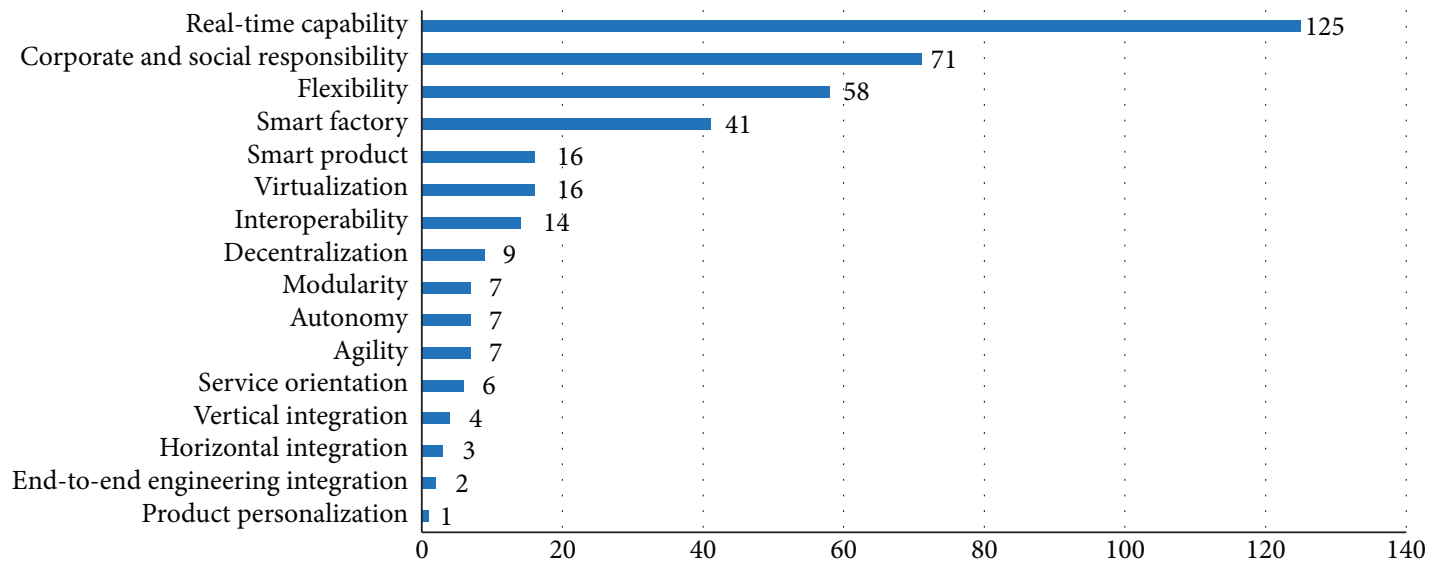

FIGURE 8: Linking optimization to the requirements and characteristics of Industry 4.0.

\section{Analysis of Industry 4.0-Related Optimization Tasks and Algorithms}

In this section, the Industry 4.0-related optimization tasks and algorithms are discussed. Typical optimization problems are generally formalized, their complexity and metric systems are determined, and the impact of changes on the development of these algorithms inducted by Industry 4.0-driven solutions is analyzed in Section 4.1. The characteristics of optimization tasks and the requirements of Industry 4.0 solutions are presented in Section 4.2. Future research areas are identified based on current trends in Section 4.3.

4.1. Formalization of the Optimization Problems. The nature of an optimization problem is determined by its constraints and objective function. The standard form of an optimization problem is as follows: 
TABLE 4: Network analysis of keywords to show the concepts related to the different requirements as well as the keywords related to the concept in parentheses.

Requirement
Internet of Things (machine learning, digital manufacturing, intelligent manufacturing, smart factory, lean

Vertical integration

Horizontal integration

End-to-end engineering

Smart factories

Product personalization

Virtualization

Decentralization

Flexibility

Corporate social responsibility

Real-time capability

Modularity

Interoperability

Smart product

Autonomy

Service orientation

Agility management, process control, wireless sensor network, smart grid); business process (digitalization, Internet of Things, cyber-physical system, digital economy); process optimization (digital twin, machine learning, supply chain, digital transformation, anomaly detection); productivity (process optimization, automation, planning, efficiency, process automation); reliability (availability, smart grid, productivity, dependability); ontology (smart manufacturing, intelligent manufacturing, artificial neural network)

Lean management (Internet of Things, digitalization, sustainable manufacturing); ontology; smart city

(Internet of Things, machine learning, cyber-physical system); security (machine learning, predictive maintenance, modeling, digital twin, anomaly detection); reinforcement learning (artificial intelligence, internet of things, deep learning, predictive maintenance, condition monitoring); resource efficiency (cloud manufacturing, sustainability, smart manufacturing network, additive manufacturing)

Sustainable manufacturing (energy optimization, lean management, artificial intelligence, Internet of Things); cyber-physical system (digital twin, smart factory, flow shop scheduling); productivity; logistics

(Internet of Things, intelligent manufacturing, digital twin, genetic algorithm, smart manufacturing)

Digital twin (cyber-physical system, smart factory); smart manufacturing (Internet of Things, digital transformation, data analytics, digital twin, supply chain, cyber-physical system, logistics); cyber-physical system; artificial intelligence (machine learning, Internet of Things, digitalization, digital twin, discrete event simulation); Internet of Things

Supply chain; job shop scheduling (automation, reinforcement learning, multi-agent systems); logistics

(Internet of Things, intelligent manufacturing, digital twin, genetic algorithm, smart manufacturing)

Digital twin (cyber-physical systems, smart factory); virtual reality (digital transformation, digital twin, key performance indicator, machining)

Supply chain (scheduling, smart manufacturing, control, planning, digital transformation); blockchain (big data analytics, additive manufacturing, digital twin, Internet of Things); cloud computing (Internet of Things, genetic algorithm, evolutionary algorithm, digitalization)

Digital transformation (virtual reality, artificial intelligence, smart manufacturing, supply chain); assembly line (optimization, digital twin)

Optimization (machine learning, scheduling, energy efficiency); monitoring (process control, optimization, Internet of Things); efficiency (lean, digital economy); sustainability; smart grid (wireless sensor network, smart grid, reliability, efficiency); digital economy (business process, efficiency); resource efficiency (additive manufacturing, cloud manufacturing, sustainability, smart manufacturing network); circular economy (demand response, modelling); energy (control, modelling, cyber-physical system); energy optimization

(digitalization, scheduling, digital factory, sustainable manufacturing); lean manufacturing (process planning, additive manufacturing, scheduling); sustainability (machine learning, optimization, modelling, resource efficiency)

Monitoring; cyber-physical system (digital twin, smart factory, flow shop scheduling); Internet of Things; digital factory (energy optimization, simulation model); flow shop scheduling (genetic algorithm, particle swarm optimization, cyber-physical system, multi-agent system); lean management (Internet of Things, sustainable manufacturing); job shop scheduling; self-optimization (artificial intelligence, reinforcement learning, intelligent manufacturing); planning (productivity, manufacturing, scheduling, metaheuristic, control); scheduling (genetic algorithm, multi-objective optimization, cloud manufacturing, modelling, cyber-physical system); data acquisition (cyber-physical system, Internet of Things, smart manufacturing); demand response (circular economy, data-driven)

Cloud computing (intelligent manufacturing, Internet of Things, genetic algorithm, data analytics); logistics; edge computing (Internet of Things, smart manufacturing, cloud computing, data analytics)

Internet of Things; sustainability; cyber-physical systems; smart factory (Internet of Things, digital twin, cyber-physical system, smart manufacturing, evolutionary algorithms, process planning); wireless sensor network (Internet of Things, smart grid); smart grid (Internet of Things, reliability, efficiency, wireless sensor network)

Smart manufacturing (Internet of Things, digital transformation, data analytics, digital twin, supply chain, cyber-physical system, logistics); smart factory (Internet of Things, digital twin, cyber-physical systems, smart manufacturing, digital manufacturing, artificial intelligence, modelling)

Self-optimization (artificial intelligence, intelligent manufacturing, reinforcement learning, digitalization);

deep learning (artificial intelligence, advanced process control, data analytics, machine learning, reinforcement learning); machine learning (internet of things, artificial intelligence, data analytic, predictive maintenance, process optimization); automation (artificial intelligence, digital twin, cyber-physical systems, digital transformation, logistics, review, planning)

Lean manufacturing (scheduling, additive manufacturing, process planning)

Wireless sensor network; smart grid; availability (interaction, dependability, reliability); reliability (availability, smart grid, productivity, dependability) 
TABLE 5: I40-relevant application areas of optimization algorithms.

\begin{tabular}{|c|c|c|c|}
\hline Keyword & Description & Illustrative applications & $\begin{array}{l}\text { Number of } \\
\text { relevant papers }\end{array}$ \\
\hline Control & $\begin{array}{l}\text { It helps to achieve and increase a consistent, } \\
\text { economical, and safe production level }\end{array}$ & $\begin{array}{l}\text { Controller for mobile robot path tracking [65] } \\
\text { A control strategy for smart energy charging } \\
{[66]}\end{array}$ & 340 \\
\hline Planning & $\begin{array}{l}\text { It is a preparatory step before manufacturing which } \\
\text { optimizes several sequences of operations }\end{array}$ & $\begin{array}{l}\text { Automating production planning and control } \\
\text { in manufacturing [67] } \\
\text { Operation planning of renewable energy [68] }\end{array}$ & 138 \\
\hline Scheduling & $\begin{array}{l}\text { It gives the optimal allocation of the available } \\
\text { resources in the given workflows }\end{array}$ & $\begin{array}{l}\text { Line balancing and AGV scheduling [59] } \\
\text { Machine scheduling [69] }\end{array}$ & 137 \\
\hline Maintenance & $\begin{array}{l}\text { It defines optimization tasks for preventing the } \\
\text { failure of expensive manufacturing equipment }\end{array}$ & $\begin{array}{l}\text { Digital twin-driven autonomous } \\
\text { maintenance [60] } \\
\text { Sensor-based maintenance policies [70] }\end{array}$ & 91 \\
\hline Energy efficiency & $\begin{array}{l}\text { It helps to reduce the energy consumption of the } \\
\text { manufacturing processes based on optimization } \\
\text { techniques }\end{array}$ & $\begin{array}{c}\text { Optimization of greenhouse production } \\
\text { process [71] } \\
\text { Energy-efficient scheduling by collaboration } \\
\text { between cyber-physical production and } \\
\text { energy systems [72] }\end{array}$ & 32 \\
\hline Topology & $\begin{array}{c}\text { It gives an answer as to how to place some materials } \\
\text { on a given surface to obtain the best structural } \\
\text { performance }\end{array}$ & $\begin{array}{c}\text { Topology optimization of an automotive } \\
\text { dashboard [73] } \\
\text { Manufacturing redesign of a piece of military } \\
\text { aircraft equipment }[74]\end{array}$ & 14 \\
\hline $\begin{array}{l}\text { Planning and } \\
\text { scheduling }\end{array}$ & $\begin{array}{l}\text { It is an integrated optimization of manufacturing } \\
\text { process planning and scheduling }\end{array}$ & $\begin{array}{c}\text { Integrated planning and scheduling problem } \\
\text { in parallel is solved by a metaheuristic } \\
\text { approach [75] } \\
\text { Cloud-based intelligent dynamic planning } \\
\text { and scheduling system [76] }\end{array}$ & 12 \\
\hline Lean management & $\begin{array}{l}\text { It focuses on minimizing waste and maximizing } \\
\text { productivity within manufacturing systems } \\
\text { simultaneously }\end{array}$ & $\begin{array}{l}\text { Process optimization by lean management } \\
\qquad[77]\end{array}$ & 9 \\
\hline $\begin{array}{l}\text { Business process } \\
\text { optimization }\end{array}$ & $\begin{array}{l}\text { It can increase the efficiency of the production, } \\
\text { delivery, and operational processes amongst others } \\
\text { in industrial environments }\end{array}$ & Improving production processes [78] & 5 \\
\hline Optimal control & $\begin{array}{l}\text { It is an optimization of control processes and } \\
\text { subsystems to support an efficient operation }\end{array}$ & Scheduling flexibly configurable jobs [52] & 5 \\
\hline $\begin{array}{l}\text { Resource } \\
\text { optimization }\end{array}$ & $\begin{array}{l}\text { It helps align available resources with the maximum } \\
\text { efficiency of goals }\end{array}$ & $\begin{array}{l}\text { Resource optimization of industrial processes } \\
\text { [79] }\end{array}$ & 2 \\
\hline
\end{tabular}

$$
\begin{array}{cl}
\underset{x}{\operatorname{minimize}} & f(\mathbf{x}) \\
& g_{i}(\mathbf{x}) \leq 0, i=1, \ldots, m, \\
\text { subject to } & h_{j}(\mathbf{x})=0, j=1, \ldots, l, \\
& \mathbf{x} \in \mathbf{R},
\end{array}
$$

where $f, g_{1}, \ldots, g_{m}, h_{1}, \ldots, h_{l}$ are $\mathbf{R}^{n} \longrightarrow \mathbf{R}$ functions.

In the following description, the models are discussed in ascending order of their computational complexity.

If an optimization task does not contain constraints, then it is a so-called unconstrained optimization problem regardless of the nature of the objective function. These tasks can be handled with traditional tools of mathematical analysis.

Optimization problems that contain only linear constraints and a linear objective function are called linear programming (LP) problems:

$$
\begin{aligned}
& \operatorname{minimize} c_{0}+\sum_{j=1}^{n} c_{j} x_{j} \\
& \text { subject to } \quad L_{i} \leq \sum_{j=1}^{n} a_{j}^{i} x_{j} \leq U_{i}, i=1, \ldots, m, \\
& l_{j} \leq x_{j} \leq u_{j}, j=1, \ldots, n .
\end{aligned}
$$

The existence of effective LP solvers is very important in optimization because they can solve a wide range of optimization problems and are often hidden engines of other algorithms. For example, lots of nonlinear models can be transformed into an equivalent LP model or solved by solving a sequence of linear models; moreover, integer programming solvers usually solve lots of LP models. The two most used solvers are the simplex method and the interior-point method. 
Typical Industry 4.0-focused linear optimization problems are either product-mix problems, where the goal is to determine the optimally produced quantities of product, or transportation problems consisting of the optimal logistics in an efficient way.

The next group of optimization problems is quadratic programming (QP) where, under linear constraints, the objective function is as follows: minimize $(1 / 2) \mathbf{x}^{T} Q \mathbf{x}+c^{T} \mathbf{x}$, where $Q$ denotes an $n \times n$-dimensional real symmetric matrix, $c$ stands for a real-valued, $i$-dimensional vector, and the decision variables are represented by the $n$-dimensional vector $\mathbf{x}$. A variety of methods can be used to handle the problem, e.g., the extended simplex algorithm and interiorpoint method. Typical QP problems are regression-based optimization problems that optimize supply and demand response, where the equilibrium price and quantity are modelled. Many QP problems are highlighted in paper [80].

The most complex optimization tasks are the group of nonlinear optimization problems (NLP), where the objective function is a nonlinear function of the decision variables and the constraints can be linear as well as nonlinear expressions. Typical Industry 4.0-focused nonlinear optimization problems are as follows: optimal control, where a control plan for a dynamical system over a period of time is optimized, and predictive maintenance, where the aim is to estimate how often system maintenance should be performed, but priority areas are energy efficiency and topology optimization, all of which effectively support the improvement of the efficiency of complex industrial systems.

A new version of the aforementioned optimization problems is obtained when the decision variables are not continuous but discrete. In the general case, this means an exponential number of steps are required to solve the tasks. Therefore, in the case of linear programming tasks, integer programming (IP) and mixed-integer linear programming (MILP), if both integer and continuous variables can occur between the decision variables, can be referred to. The standard form of the problem is as follows:

$$
\begin{array}{ll}
\operatorname{minimize} c^{T} \mathbf{x}+h^{T} \mathbf{y} \\
& A \mathbf{x}+D \mathbf{y}=b \\
\text { subject to } & \mathbf{x}, \mathbf{y} \geq 0 \\
& \mathbf{x} \text { integer }\left(\mathbf{x} \in \mathbf{Z}^{n}\right) .
\end{array}
$$

Very often, the integer variables are bounded, i.e., $0 \leq \mathbf{x} \leq u$. To efficiently handle an optimization problem, a suitable methodology and mathematical solver need to be chosen to take into account the nature of the problem. An integer programming model of the assignment problem is an illustrative example here, where the jobs and workers are assigned in an optimal way. Similarly, scheduling problems can be described by (mixed) integer models that help optimize both manufacturing steps and business processes in the manufacturing environment.

The multiobjective optimization model is developed when more than one objective function is optimized simultaneously. In the case of nontrivial models, it can be said that no single solution is optimal for all goals, since the objective functions work against each other. Basically, two approaches are available to solve multiobjective optimization models: traditional methods using single-objective functions and optimization algorithms based on a Pareto front. The nature of the objective functions and the constraint conditions determine the complexity of as well as difficulty in solving the problem. A review of multiobjective optimization frameworks, models, and algorithms is summarized in [81]. The standard form of the multiobjective problem is as follows:

$$
\begin{array}{ll}
\operatorname{minimize}= & \left\{f_{1}(\mathbf{x}), f_{2}(\mathbf{x}), \ldots, f_{m}(\mathbf{x})\right\} \\
& g_{i}(\mathbf{x}) \leq 0, i=1, \ldots, s_{1} \\
\text { subject to } & h_{j}(\mathbf{x})=0, j=1, \ldots, s_{2} \\
& l_{k} \leq x_{k} \leq u_{k}, k=1, \ldots, n .
\end{array}
$$

where $\mathbf{x}=\left(x_{1}, x_{2}, \ldots, x_{n}\right)$ denotes an $n$-dimensional vector of decision variables and $\mathbf{z}=\left(z_{1}, z_{2}, \ldots, z_{m}\right)$ stands for an $m$-dimensional vector of objective functions. Function $g_{i}$ represents the inequality constraint $i$ and function $h_{j}$ yields the equality constraint $j$, where the number of these constraints are $s_{1}$ and $s_{2}$, respectively. The lower and upper bounds on the decision variable $x_{k}$ are represented by $l_{k}$ and $u_{k}$. Regardless of the mathematical model, each optimization problem can be converted into a multiobjective programming problem if further objective functions are added to the set of constraints (for example, should not only cost but also time and reliability be optimized).

Modelling and handling uncertainties cannot be avoided in Industry 4.0-focused optimization tasks. Different modelling strategies exist in terms of optimization that takes into account uncertainties: one approach is stochastic programming, where the standard two-stage paradigm can be applied. Here, the goal is to choose the first-stage variables in such a way that the sum of the overall cost during the first stage and the expected value of the second stage is minimal. The stochastic programming model can be a linear, integer, or nonlinear problem, depending on the nature of the given task. The standard formulation of the two-stage stochastic linear program is as follows:

$$
\begin{aligned}
& \operatorname{minimizec}^{T} \mathbf{x}+E_{\xi}[Q(\mathbf{x}, \xi)] \\
& \text { subject to } A \mathbf{x}=b, \mathbf{x} \geq 0 \\
& \text { where } Q(\mathbf{x}, \xi)=\operatorname{minimize}\left\{q^{T} \mathbf{y} \mid T \mathbf{x}+W \mathbf{y}=h, \mathbf{y} \geq 0\right\}
\end{aligned}
$$

where vectors $\mathbf{x}$ and $\mathbf{y}$ represent the first- and second-stage decision variables. The elements $T, W, h$, and $q$ of the second stage can be random, and thus, $\xi=(q, h, T, W)$ is a random vector. Note that matrices $T$ and $W$ are called the technology and recourse matrices, respectively. By transforming the objective function, a stochastic programming model can also be considered as robust, where the objective function also includes the measure of variability and the risk tolerance of the modeller. In addition, if the reliability of the given system is highlighted and uncertainty in the parameters of the constraints is assumed, then the probabilistic programming approach can provide the right model representation. 
Another approach to modelling optimization problems that takes into account uncertainties is fuzzy mathematical programming. The fundamental difference between stochastic and fuzzy optimizations is in the description of uncertainty since the membership function represents the different realizations of uncertainty. Based on the above, the parameters, constraints, and the objective function can be represented by fuzzy numbers, fuzzy sets, and the fuzzy goal, respectively. In such cases, the flexible programming and possibilistic programming strategies can provide appropriate solutions. Finally, it is also worth mentioning solutions based on stochastic dynamic programming, since uncertainty can be an integral part of the technique. The solution assumes that a given time point is entirely determined by its history. Therefore, first, the tail subproblems are managed, from which the solution to the original problem can be derived. To determine the solution, a large number of computation steps and time requirements must be used in the calculation, which increases exponentially as a function of the number of variables in the model. In recent years, a number of papers have been published in the fields of stochastic programming, fuzzy programming, and stochastic dynamic programming related to Industry 4.0 applications, e.g., production planning, scheduling, capacity expansion, energy investment as well as the design and optimization of complex chemical engineering systems. Sahinidis presents a state-of-the-art optimization that takes into account uncertainty in [82].

Many optimization problems can be represented by networks such as Petri nets [83], P-graphs [84], and StateTask Networks [85]. These approaches can visualize the problem to aid understanding. Efficient solution algorithms usually exist for network type problems which can exploit the structure of the problem. Unlike general methods, these algorithms are specialized, i.e., cannot solve other types of problems.

Two groups of solvers can be used to solve MIP models, namely, exact optimization algorithms and approximate algorithms. Exact algorithms can always generate the optimal solution of the model, but the size of the solvable models is insufficient for industrial needs. Approximate algorithms are faster, so they can solve bigger problems, but usually, the quality of the solution cannot be guaranteed. Numerous solution methods are available, but the aim of this paper is not to review all of these traditional algorithms.

The types of most typical optimization problems are given in Table 6.

4.2. Characteristics of Optimization Tasks: Requirements of Industry 4.0 Solutions. Classical optimization models have typical characteristics. These properties are summarized in Table 7 based on [118]. The table lists the key features of an optimization task that are critical to the solution.

The size of a system affects the size of its model, and the size of a model drastically affects its solution time. Determining the optimal solution of a large problem is difficult as the computational time may be impractical. Horizontal and vertical integration increases the size of a suitable model.
Every manufacturing system has some kinds of natural modular structure where tight or loose connections are found between the modules. Modules can have their own optimization models, and their connections can be modelled using additional constraints. This modularity can help to solve a model using multistage optimization techniques; moreover, the models of modules can be solved in parallel. Multistage optimization techniques are usually faster than traditional ones but cannot guarantee to calculate the global optimum.

The complexity of words has multiple meanings in terms of optimization. The Oxford English Dictionary defines complexity as, "The state or quality of being intricate, complicated or complex." This meaning can be used as a property of a manufacturing system (system complexity). Wiendahl and Scholtissek [119] divide the definition of complexity in industrial manufacturing into the complexity of the products and complexity in production. Bozarth et al. [120] introduced detail complexity as the distinct number of components of the system and dynamic complexity as the unpredictability of a system's response. Deshmukh et al. [121] used the terms static complexity which can be viewed as "a function of the structure of the system, connective patterns, variety of components, and the strengths of interactions" and dynamic complexity which is "concerned with unpredictability in the behavior of the system over a time period." A mathematical model also can be complex in terms of system complexity, i.e., it can consist of many variables and constraints; moreover, the objective function and/or the constraints can be nonlinear. Usually, a complex system results in a complex model.

The computational complexity (also referred to as the time complexity) means a classification of algorithms and problems. For an algorithm, the classification means the number of steps needed to solve a problem according to the size of the input. From this point of view, polynomial algorithms can be distinguished from nonpolynomial ones since polynomial algorithms are faster. The complexity of a problem is the complexity of the best algorithm that can solve it. As a result, $\mathrm{P}$ (polynomial) problems can be distinguished from NP (nonpolynomial) ones. If a problem belongs to the NP class, a polynomial algorithm has yet to be found which can solve it. By increasing the size of an NP problem, its solution time is increased in a nonpolynomial way (e.g., exponential, factorial, and double exponential). Ausiello et al. [122] identified more than $200 \mathrm{NP}$ optimization problems. In manufacturing, many well-known NP problems can be found, e.g., scheduling and process network synthesis. If the computational complexity of a model is high, then the solution time can be impractical for problems on an industrial scale.

An exact algorithm can generate an optimal (or nearoptimal) solution for the model and an optimal solution for the model which is not necessarily an optimal solution to the problem. The quality of the solution depends on the quality of the model, i.e., only a good model results in a good solution. In the case of approximate methods, the quality of the solution not only depends on the quality of the model but also on the methods because these algorithms usually cannot guarantee optimality. 
TABLE 6: Types of optimization problems.

\begin{tabular}{lcc}
\hline Optimization models & Model type & Example \\
\hline Stochastic programming & Uncertainty optimization & {$[69,86-88]$} \\
Robust optimization & Uncertainty optimization & {$[89-91]$} \\
Global optimization & Deterministic, continuous, unconstrained/constrained optimization & {$[92-94]$} \\
Mixed-integer nonlinear programming & Deterministic, continuous, constrained, nonlinear programming & {$[95-97]$} \\
Network optimization & Deterministic, continuous, constrained optimization & {$[98,99]$} \\
Derivative-free optimization & Deterministic, continuous, constrained, bound constrained optimization & {$[100-102]$} \\
Quadratic programming & Deterministic, continuous, constrained, linearly constrained optimization & {$[103-105]$} \\
Linear programming & Deterministic, continuous, constrained, linearly constrained optimization & {$[106-108]$} \\
Integer linear programming & Deterministic, discrete & {$[109-111]$} \\
Combinatorial optimization & Deterministic, discrete & {$[112-114]$} \\
Multiobjective optimization & - & {$[115-117]$} \\
\hline
\end{tabular}

TABle 7: Typical characteristics of classical optimization models.

\begin{tabular}{|c|c|c|}
\hline Property & Description & Trend \\
\hline Size & $\begin{array}{l}\text { The number of decision variables, parameters, } \\
\text { and constraints }\end{array}$ & $\begin{array}{l}\text { Increasing continuously because the vertical and horizontal integration } \\
\text { increases the size of the manufacturing system (supply chain) to be } \\
\text { modelled }\end{array}$ \\
\hline Modularity & $\begin{array}{l}\text { High level of modularity can help to solve the } \\
\text { model efficiently }\end{array}$ & $\begin{array}{c}\text { Important because the production systems are modular and have } \\
\text { hierarchic structure; moreover, the modules may be solved } \\
\text { independently decreasing the necessary solution time, and they can be } \\
\text { solved parallel }\end{array}$ \\
\hline Complexity & $\begin{array}{l}\text { Complexity and nonlinearity may affect the } \\
\text { solution time and precision dramatically }\end{array}$ & $\begin{array}{l}\text { Increasing because only a complex and detailed model can describe a } \\
\text { complex system appropriately }\end{array}$ \\
\hline $\begin{array}{l}\text { Time scale/ } \\
\text { adaptability }\end{array}$ & $\begin{array}{l}\text { Optimization techniques often require a } \\
\text { relatively long time to give the solution }\end{array}$ & $\begin{array}{l}\text { Important because the computational time can be critical for short- } \\
\text { term problems especially for real-time problems; moreover, the } \\
\text { flexibility of manufacturing systems is an expectation }\end{array}$ \\
\hline Solution quality & $\begin{array}{l}\text { A measure of how far a solution is at most from } \\
\text { an optimal solution is obtained }\end{array}$ & $\begin{array}{c}\text { Important for long-term problems, but for short-term problems the } \\
\text { computational time is more critical }\end{array}$ \\
\hline
\end{tabular}

4.3. Future Research and Development Directions. As is mentioned above, the solution time is very critical in industry, especially for real-time problems. For NP problems, no algorithms are known, which can quickly generate their optimal solutions. To obtain a good but not necessarily optimal solution, fast heuristic approaches are needed. Heuristics should result in simpler models where some less important details are neglected or in heuristics-based algorithms, e.g., genetic algorithm, ant colony algorithm, tabu search, and artificial intelligence-based approaches.

One of the reasons for the existence of real-time problems is the uncertainty of systems which arises from unexpected tasks and events, e.g., a breakdown of a machine which is in need of maintenance [123]. Furthermore, the environment in which the production system has to work is uncertain and constantly changing. This property originates from changes in customer demands, product design, and processing technology. Handling these uncertainties is a challenge in many fields $[124,125]$. Obviously, it becomes ambiguous which solution can be considered as optimal, e.g., the most robust one and the one expected to generate the highest profit. In this area, two main directions of research exist. In the first, the solution must be determined a priori and cannot be modified after the realization of an uncertain event. In the second, a plan exists, and when an uncertain event occurs, a reoptimization must be performed. Unlike in the previous case, the optimization is carried out when the system is already running; therefore, usually a very limited amount of time is available to deliver the solution. As a result, heuristics are often favored for this purpose because for real-time problems, a feasible solution should be sufficient which does not cause big changes compared to the original plan. Naturally, many developments do not fit into these two categories, e.g., in two-stage methods, the first stage defines an initial plan, but some decisions are later altered in the second stage during its operation.

4.3.1. Multistage Optimization. Multistage optimization is very frequent in Industry 4.0 because (horizontal and vertical) integration yields large-scale models which cannot be solved in a reasonable period of time. In high-level stages, only the "important" decisions are made and the "less important" ones are relaxed, while in lower-level stages, the "important" decisions come from the higher levels. For example, the ISA-95 standard defines 4 stages, namely, production planning, production scheduling, operating instructions, and process optimization (see Figure 2). Production planning defines which products will be manufactured; production scheduling provides the timetable of the manufacturing of the selected products, and the last two stages deal with optimizing the operations. The decentralization requirement of Industry 4.0 also points to multistage optimization because it also results in the decentralization of 
decision-making. For example, in the case of scheduling problems, Rossit et al. [126] showed that this decentralization is one of the main research directions.

Rolling horizon decision-making is a good choice for optimal decisions in a stochastic, dynamically changing environment. It is the task of the decision-maker to make a decision for a certain number of future periods in such a way that the optimal decisions made for the first period effectively support future plans. The second decision time period starts with a replanning periodicity step where previously made decisions can be revised and updated. This redesign procedure is repeated for every time period to refine and clarify future plans, i.e., rolling horizon systems iteratively solve a series of optimization problems over a shorter period. One of the most common applications of rolling horizon designs is connected to production planning problems in which decisions are made where demand is satisfied at a minimal cost. The rolling horizon planning problem has been classified by Sahin et al. [127] who focused on deterministic and stochastic demands, single and multiple planning layers, single and multiple manufacturing layers, and single and multiple items. Rolling horizon optimization problems mainly focus on optimizing the different parameters of the planning problem, e.g., the length of the planning horizon, stock level, and forecast errors. The integration of planning and scheduling in a rolling horizon is taken much less into account due to the complexity of the optimization tasks examined. Rolling operation poses some Industry 4.0-focused optimization tasks, e.g., production scheduling, supply chain planning, optimization of planning horizon parameters and lot-sizing and scheduling decisions, the investigation of the planning frequency in production systems, the impact of forecast errors in planning processes, or the examination of the lot-sizing, parallel machine lotsizing, and scheduling problems.

4.3.2. Digital Twin. Cyber-physical systems often have digital twins as building elements. The cyber part of a digital twin is suitable for performing various calculations and simulations [128] and, moreover, can provide information about optimization and scheduling algorithms [129]. Knowledge-based digital twin solutions can also help optimize the production [130] as they can be used to support decisions based on simulations, predictions, and optimization before providing intelligent real-time control as is depicted in Figure 9.

Digital twin solutions have already been applied for ergonomic optimization [131], optimizing the behavior of the system during the design phase [132] and multirobot manufacturing cell optimization [47]. Process simulations are also possible [133]. The approach seems to have become a key enabler of further Industry 4.0 solutions and their optimizations in the future, e.g., autonomous maintenance [60]. There has never been a full digital twin application in the field of pharmaceutical manufacturing [134]. Furthermore, this technology has never been implemented in cloud platforms; however, there is a need to build connections between these Industry 4.0 solutions [135]. The support of optimal product design using digital twin solutions is also a serious challenge for future research [136].

4.3.3. Ontology-Based Knowledge Representation and Integration. Ontology is a formal model that uses mathematical logic to clarify and define things as well as their relations [137]. Since they can be described by mathematical models, it is possible to implement them into a computerized environment.

Ontology-based design is not yet widespread and, therefore, seems to be a future research direction. However, initiatives for cyber-physical systems already exist [138]. Ontologies have also been constructed to support the decision-making of agents, and therefore, the agility and flexibility requirements have been met too [139].

Based on XML, several ontology formats have been developed such as B2MML (Business to Manufacturing Markup Language) and AutomationML (Automation Markup Language). B2MML is based on the ISA-95 standard and aims to support the vertical integration process with appropriate data conversion solutions and the efficient design of information exchange [140]. Firstly, useful information to be exchanged has to be identified and aspects are commonly provided by process models [141]. Subsequently, a control system supervises and schedules the exchange of data. The workflow using B2MML can be easily presented for scheduling [142]. This cycle is illustrated in Figure 10. The production data must be collected first via B2MML which is the input of the scheduling algorithm. The output is shared with the given dispatching system and compared with the process model. If the process seems to be inefficient, the production parameters are changed.

AutomationML (Automation Markup Language) is an XML-based data format for exchanging information between modern automation engineering tools [143]. It provides a hierarchical description language for industrial systems that takes into consideration both structure and properties [144]. AutomationML is very popular, widely accepted, and supported by different companies as well as suppliers. By using AutomationML, the overall process becomes faster and independent of the knowledge and experience of design engineers [145]. The structure of AutomationML consists of individual devices called "instances." They can be classified hierarchically into groups represented as "system unit classes." The entire system is named an "instance hierarchy." The interconnections between units are called "internal links" [146]. AutomationML offers suitable data collection and preprocessing opportunities by being combined with model-driven engineering [147]. This integration can reduce manual effort and increase reusability. AutomationML can be extended by performance metrics and used for optimization [144].

\section{Discussion and Conclusions}

Industry 4.0 aims for comprehensive automation and integration to achieve the most efficient, optimal operation. Although countless studies have been published, no review 


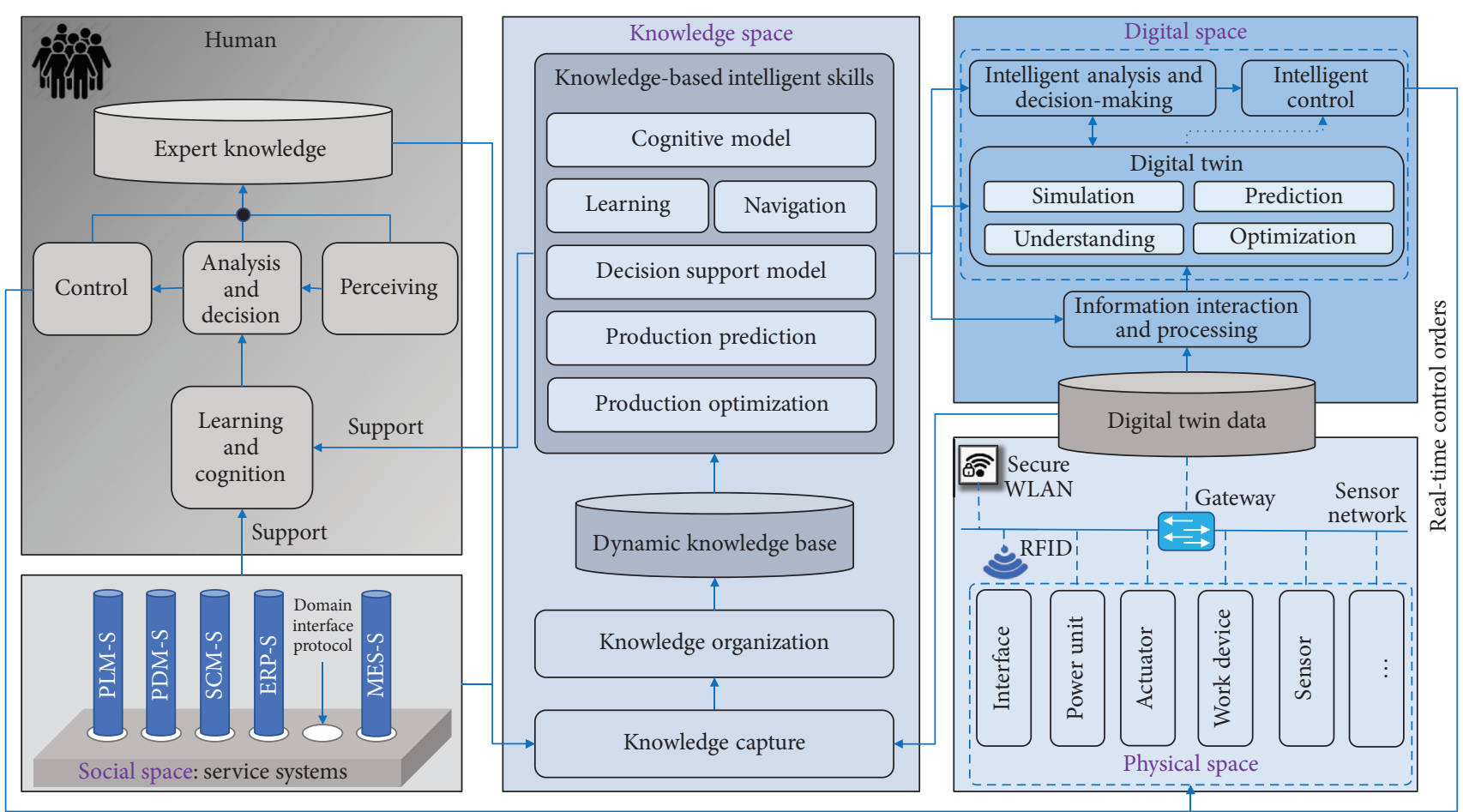

FIGURE 9: Architecture of knowledge-based digital twin solutions. The digital world and humans can collaboratively control the physical space and the knowledge space that supports it. The experiences are also saved and, therefore, captured.

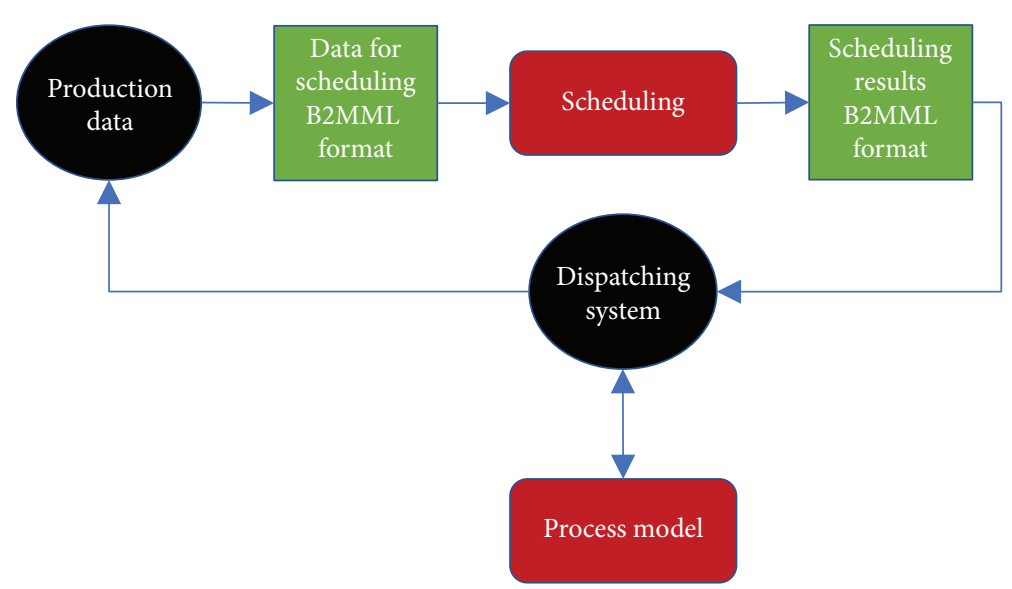

Figure 10: The workflow using B2MML for scheduling.

papers have been written about the optimization solutions of Industry 4.0. This paper provides an overview of the optimization methods and algorithms defined by the Industry 4.0 trend. The driving force behind these solutions is primarily integration, vertical and horizontal in particular.

Vertical integration aims to achieve the internal integration of enterprises from the production level to the business level. Planning scheduling and operation tasks are becoming increasingly dependent on each other, so the three aforementioned tasks need to be addressed simultaneously, and in an integrated way, moreover, real-time optimization plays an important role. Horizontal integration aims to organize the total supply chain management from the supplier to the customer, which needs to be thoroughly optimized. Tools must be developed for the simultaneous optimization of different global tasks such as scheduling, maintenance, production, and logistics. Horizontal integration also facilitates data exchange for analyzing processes, and its investigation can identify inefficient processes. A related concept known as collaborative manufacturing management has been presented. It is also clear that horizontal and vertical integration must be applied simultaneously to achieve the most efficient operation and also facilitate further optimization opportunities such as the implementation of lean tools.

The requirements of Industry 4.0 have been collected and discussed. These principles can provide guidance while developing new Industry 4.0 solutions. All of these 
requirements have different effects on optimization and sometimes stand in conflict with each other in practice. However, solutions and concepts must be found to meet these requirements. Some examples were collected, which offer ideas for development. Keywords, which can define concepts, were also investigated by network analysis and help solve a given requirement properly based on the linkages. Such a table has also been presented which can determine research and development directions. Keyword analysis also revealed the connections between keywords and their structure. The derived framework is distributed for different areas like applications, algorithms, and enabling technologies.

After the discussion of integration methods and requirements, a quantitative analysis of the related publications was presented. The publications over time show an ascending trend and it can be observed that $80 \%$ of the papers were published by many journals between 2018 and 2020 (until October). The number of most frequently occurring keywords in published papers about given requirements was counted. Internet of Things, digital twin, and simulations were the keywords that most frequently occurred. Real-time capability, corporate social responsibility, and flexibility are the top 3 most researched topics among the requirements. Relevant application areas and their illustrative examples were also collected. Control, planning, and scheduling were the most popular topics.

A large number of optimization problems to be solved in industrial environments exist which, in many cases, require the application of complex solution methods. This paper has identified a range of key Industry 4.0 focus issues such as management, planning, scheduling, and maintenance, tasks of which all can be described as complex optimization problems through their interconnections. As has been pointed out, the starting point of optimization tasks is the continuous, integer, and mixed-integer linear programming tasks, on which the processes of the production environment can be modelled and examined more and more accurately. Given the uncertainty of modelling, incorporating the diversity of objective functions into the model and considering nonlinear relationships help the design to become increasingly accurate. Based on all of the aforementioned points, it is clear that the size of the mathematical models set up, their complexity, the modularity of the problem, and solution stability are key factors. All these have a decisive effect on the solution of the set optimization tasks, their accuracy, and their management using computer software. The difficulty in determining a solution is well illustrated by the fact that solving integer-value optimization tasks requires an exponential number of steps from mathematical solvers. For example, a scheduling task itself formulates a difficult NP task, which is integrated many times with other production and operational requirements; therefore, identifying the optimal solution is a growing challenge. All of these difficulties can be reduced by decomposing models as well as applying effective modelling and heuristics. With formal methods, the optimal solution can be validated with simulation tools; moreover, by using digital twins, the detailed efficiency-improving role can be seen as well.

\section{Conflicts of Interest}

The authors declare that they have no conflicts of interest.

\section{Acknowledgments}

This work was supported by the TKP2020-NKA-10 Project financed under the 2020-4.1.1-TKP2020 Thematic Excellence Programme by the National Research, Development and Innovation Fund of Hungary.

\section{References}

[1] C. Ierardi, L. Orihuela, and I. Jurado, "Distributed estimation techniques for cyber-physical systems: a systematic review," Sensors, vol. 19, no. 21, p. 4720, 2019.

[2] M. Dziubany, L. Creutz, S. Kopp, J. Schneider, A. Schmeink, and G. Dartmann, "Development of a cyber-physical system for an autonomous indoor transportation service," in Proceedings of the 2020 9th Mediterranean Conference on Embedded Computing (MECO), pp. 1-5, IEEE, Budva, Montenegro, June 2020.

[3] B. A. Osei, N. A. Ragavan, and H. K. Mensah, "Prospects of the fourth industrial revolution for the hospitality industry: a literature review," Journal of Hospitality and Tourism Technology, vol. 11, no. 3, pp. 479-494, 2020.

[4] L. Monostori, B. Kádár, T. Bauernhansl et al., "Cyberphysical systems in manufacturing," CIRP Annals, vol. 65, no. 2, pp. 621-641, 2016.

[5] N. Sihag and K. S. Sangwan, "A systematic literature review on machine tool energy consumption," Journal of Cleaner Production, vol. 275, p. 123125, 2020.

[6] A. Angelopoulos, E. T. Michailidis, N. Nomikos et al., "Tackling faults in the industry 4.0 era-a survey of machinelearning solutions and key aspects," Sensors (Switzerland), vol. 20, no. 1, p. 109, 2020.

[7] A. Goienetxea Uriarte, A. H. C. Ng, and M. Urenda Moris, "Bringing together lean and simulation: a comprehensive review," International Journal of Production Research, vol. 58, no. 1, pp. 87-117, 2020.

[8] J. Prinsloo, S. Sinha, and B. von Solms, "A review of industry 4.0 manufacturing process security risks," Applied Sciences, vol. 9, no. 23, p. 5105, 2019.

[9] D. Moher, L. Shamseer, M. Clarke et al., "Preferred reporting items for systematic review and meta-analysis protocols (PRISMA-P) 2015 statement," Systematic Reviews, vol. 4, no. 1, p. 1, 2015.

[10] F. S. Costa, S. M. Nassar, S. Gusmeroli et al., "FASTEN IIoT: an open real-time platform for vertical, horizontal and endto-end integration," Sensors, vol. 20, no. 19, p. 5499, 2020.

[11] A. Seyedamir, B. R. Ferrer, and J. L. M. Lastra, "An ISA-95 based ontology for manufacturing systems knowledge description extended with semantic rules," in Proceedings of the 2018 IEEE 16th International Conference on Industrial Informatics (INDIN), pp. 374-380, IEEE, Porto, Portugal, July 2018.

[12] B. Wally, C. Huemer, and A. Mazak, "Entwining plant engineering data and ERP information: vertical integration with AutomationML and ISA-95," in Proceedings of the 2017 3rd International Conference on Control, Automation and Robotics (ICCAR), pp. 356-364, IEEE, Nagoya, Japan, April 2017.

[13] A. Semmar, N. Machkour, R. Boutaleb et al., "Modeling input data of control system of a mining production unit 
based on ISA-95 approach," in Proceedings of the International Conference on Smart Applications and Data Analysis, pp. 47-55, Springer, Marrakesh, Morocco, June 2020.

[14] J. Sun, H. Yamamoto, and M. Matsui, "Horizontal integration management: an optimal switching model for parallel production system with multiple periods in smart supply chain environment," International Journal of Production Economics, vol. 221, p. 107475, 2020.

[15] J. Bechtold, A. Kern, C. Lauenstein, and L. Bernhofer, Industry 4.0-The Capgemini Consulting View Capgemini Consulting, Paris, France, November 2020, https://www.capgemini.com/ consulting/wp-content/uploads/sites/30/2017/07/capgeminiconsulting-industrie-4.0_0_0.pdf.

[16] X. Xue, Y. M. Kou, S. F. Wang, and Z. Z. Liu, "Computational experiment research on the equalization-oriented service strategy in collaborative manufacturing," IEEE Transactions on Services Computing, vol. 11, no. 2, pp. 369-383, 2016.

[17] ARC Advisory Group, Collaborative Manufacturing Management Strategies, ARC Strategies, Sacramento, CA, USA, 2002.

[18] M. R. Firmansyah and Y. Amer, "A review of collaborative manufacturing network models," International Journal of Materials, Mechanics and Manufacturing, vol. 1, no. 1, pp. 6-12, 2013.

[19] M. Mladineo, S. Celar, L. Celent, and M. Crnjac, "Selecting manufacturing partners in push and pull-type smart collaborative networks," Advanced Engineering Informatics, vol. 38, pp. 291-305, 2018.

[20] S. Kuik and L. Diong, "A model-driven decision approach to collaborative planning and obsolescence for manufacturing operations," Industrial Management \& Data Systems, vol. 119, no. 9, pp. 1926-1946, 2019.

[21] Y. Cheng, L. Bi, F. Tao, and P. Ji, "Hypernetwork-based manufacturing service scheduling for distributed and collaborative manufacturing operations towards smart manufacturing," Journal of Intelligent Manufacturing, vol. 31, no. 7, pp. 1707-1720, 2018.

[22] L. Pérez, S. Rodríguez-Jiménez, N. Rodríguez, R. Usamentiaga, D. F. García, and L. Wang, "Symbiotic human-robot collaborative approach for increased productivity and enhanced safety in the aerospace manufacturing industry," The International Journal of Advanced Manufacturing Technology, vol. 106, no. 3-4, pp. 851-863, 2020.

[23] K. Lu, Q. Han, G. Zhu, and B. Huang, "Research on the whole process security system framework of network collaborative manufacture," in Proceedings of the 2020 Chinese Control and Decision Conference (CCDC), pp. 5530-5534, IEEE, Hefei, China, August 2020.

[24] P. Helo, Y. Hao, R. Toshev, and V. Boldosova, "Cloud manufacturing ecosystem analysis and design," Robotics and Computer-Integrated Manufacturing, vol. 67, p. 102050, 2021.

[25] W. de Paula Ferreira, F. Armellini, and L. A. De SantaEulalia, "Simulation in industry 4.0: a state-of-the-art review," Computers \& Industrial Engineering, vol. 149, p. 106868, 2020.

[26] H. Lasi, P. Fettke, H.-G. Kemper, T. Feld, and M. Hoffmann, "Industry 4.0," Business \& Information Systems Engineering, vol. 6, no. 4, pp. 239-242, 2014.

[27] M. Hermann, T. Pentek, and B. Otto, "Design principles for industrie 4.0 scenarios: a literature review," in Proceedings of the 2016 49th Hawaii International Conference on System
Sciences (HICSS), vol. 1, pp. 3-15, Koloa, HI, USA, January 2015.

[28] M. Hermann, T. Pentek, and B. Otto, "Design principles for industrie 4.0 scenarios," in Proceedings of the 2016 49th Hawaii International Conference on System Sciences (HICSS), pp. 3928-3937, Koloa, HI, USA, January 2016.

[29] A. Chiarini and M. Kumar, "Lean six sigma and industry 4.0 integration for operational excellence: evidence from Italian manufacturing companies," Production Planning and Control, pp. 1-18, 2020.

[30] M. Meyer-Hentschel, O. Lohse, S. Rao, and R. Lepratti, "Manufacturing operations management for smart manufacturing-a case study," in Advances in Production Management Systems. The Path to Digital Transformation and Innovation of Production Management Systems, pp. 91-98, Springer International Publishing, Cham, Switzerland, 2020.

[31] A. Ahmadi, A. H. Sodhro, C. Cherifi, V. Cheutet, and Y. Ouzrout, "Evolution of 3C cyber-physical systems architecture for industry 4.0," in Service Orientation in Holonic and Multi-Agent Manufacturing Cham, T. Borangiu, D. Trentesaux, A. Thomas, and S. Cavalieri, Eds., pp. 448459, Springer International Publishing, Cham, Switzerland, 2019.

[32] A. J. H. Redelinghuys, A. H. Basson, and K. Kruger, "A sixlayer architecture for the digital twin: a manufacturing case study implementation," Journal of Intelligent Manufacturing, vol. 31, no. 6, pp. 1383-1402, 2020.

[33] E. Kavakli, J. Buenabad-Chávez, V. Tountopoulos, P. Loucopoulos, and R. Sakellariou, "Specification of a software architecture for an industry 4.0 environment," in Proceedings of the 2018 6th International Conference on Enterprise Systems ES, pp. 36-43, Limassol, Cyprus, October 2018.

[34] A. K. Sahu, A. K. Sahu, and N. K. Sahu, "A review on the research growth of industry 4.0," International Journal of Business Analytics, vol. 7, no. 1, pp. 77-97, 2020.

[35] O. Nwauka, A. Telukdarie, and J. Enslin, "Virtual power plant basic requirements for integration of distributed energy resources, driven by industry 4.0," in Proceedings of the International Conference on Industrial Engineering and Operations Management; 2018, pp. 511-523, Paris, France, July, 2018.

[36] M. Ringhofer, G. Wimmer, J. F. Plaul, E. Tatschl-Unterberger, and K. Herzog, "Transition of the steelmaking industry to digital technologies," Chernye Metally, no. 3, pp. 12-17, 2018.

[37] I. Hardai, B. Illés, and Á. Bányai, "Efficiency improvement of reverse logistics in industry 4.0 environment," in Proceedings of the 1st International Conference on Engineering Solutions for Sustainable Development (ICESSD 2019), pp. 169-177, Miskolc, Hungary, October 2019.

[38] D. Ivanov, A. Dolgui, A. Das, and B. Sokolov, "Digital supply chain twins: managing the ripple effect, resilience, and disruption risks by data-driven optimization, simulation, and visibility," in Handbook of Ripple Effects in the Supply Chain, D. Ivanov, A. Dolgui, and B. Sokolov, Eds., Springer International Publishing, Cham, Switzerland, pp. 309-332, 2019.

[39] O. Protalinsky, A. Khanova, and I. Shcherbatov, "Simulation of power assets management process," in Recent Research in Control Engineering and Decision Making Cham, O. Dolinina, A. Brovko, V. Pechenkin, A. Lvov, V. Zhmud, 
and V. Kreinovich, Eds., Springer International Publishing, Cham, Switzerland, pp. 488-501, 2019.

[40] E. Hozdić, "Smart factory for industry 4.0: a review," International Journal of Modern Manufacturing Technologies, vol. 7, no. 1, pp. 28-35, 2015.

[41] D. Sun, R. Huang, Y. Chen et al., "PlanningVis: a visual analytics approach to production planning in smart factories," IEEE Transactions on Visualization and Computer Graphics, vol. 26, pp. 579-589, 2020.

[42] J. Wan, M. Yi, D. Li, C. Zhang, S. Wang, and K. Zhou, "Mobile services for customization manufacturing systems: an example of industry 4.0," IEEE Access, vol. 4, pp. 89778986,2016

[43] R. Rolle, V. Martucci, and E. Godoy, "Architecture for digital twin implementation focusing on industry 4.0," IEEE Latin America Transactions, vol. 18, no. 5, pp. 889-898, 2020.

[44] T. Nishi, M. Matsuda, M. Hasegawa, R. Alizadeh, Z. Liu, and T. Terunuma, "Automatic construction of virtual supply chain as multi-agent system using enterprise E-catalogues," International Journal of Automation Technology, vol. 14, no. 5, pp. 713-722, 2020.

[45] X. Ma, J. Wang, Q. Bai, and S. Wang, "Optimization of a three-echelon cold chain considering freshness-keeping efforts under cap-and-trade regulation in Industry 4.0," International Journal of Production Economics, vol. 220, p. 107457, 2020.

[46] E. Chacon, J. Albarrán, and L. Cruz Salazar, "The control of water distribution systems as a holonic system," in Service Oriented, Holonic and Multi-Agent Manufacturing Systems for Industry of the Future, pp. 352-365, Springer International Publishing, Cham, Switzerland, 2020.

[47] L. Pérez, S. Rodríguez-Jiménez, N. Rodríguez, R. Usamentiaga, and D. F. García, "Digital twin and virtual reality based methodology for multi-robot manufacturing cell commissioning," Applied Sciences, vol.10, no. 10, p. 3633, 2020.

[48] V. K. Chawla, S. Angra, S. Suri, and R. S. Kalra, "A synergic framework for cyber-physical production systems in the context of industry 4.0 and beyond," International Journal of Data and Network Science, vol. 4, pp. 237-244, 2020.

[49] M. Trstenjak, T. Opetuk, H. Cajner, and N. Tosanovic, "Process planning in industry 4.0-current state, potential and management of transformation," Sustainability, vol. 12, no. 15 , p. 5878, 2020.

[50] N. I. Giannoccaro, G. Persico, S. Strazzella, A. Lay-Ekuakille, and P. Visconti, "A system for optimizing fertilizer dosing in innovative smart fertigation pipelines: modeling, construction, testing and control," International Journal of Precision Engineering and Manufacturing, vol. 21, no. 1, pp. 1581-1596, 2020.

[51] M. Pekarcikova, P. Trebuna, M. Kliment, and L. Rosocha, "Material flow optimization through E-kanban system simulation," International Journal of Simulation Modelling, vol. 19, no. 2, pp. 243-254, 2020.

[52] D. Ivanov, B. Sokolov, F. Werner, and A. Dolgui, "Proactive scheduling and reactive real-time control in industry 4.0," in Scheduling in Industry 4.0 and Cloud Manufacturing, B. Sokolov, D. Ivanov, and A. Dolgui, Eds., pp. 11-37, Springer International Publishing, Cham, Switzerland, 2020.

[53] J. Aston and R. P. Freire, "The car as a transformer," in Intelligent Human Systems Integration 2020, T. Ahram, W. Karwowski, A. Vergnano, F. Leali, and R. Taiar, Eds., pp. 118-123, Springer International Publishing, Cham, Switzerland, 2020.
[54] V. Colla, V. Iannino, J. Denker, and M. Göttsche, "A CPSbased simulation platform for long production factories," Metals-Open Access Metallurgy Journal, vol. 9, no. 10, p. 1025, 2019.

[55] V. Slaný, A. Lučanský, P. Koudelka, J. Mareček, E. Krčálová, and R. Martínek, "An integrated IoT architecture for smart metering using next generation sensor for water management based on LoRaWAN technology: a pilot study," Sensors, vol. 20, no. 17, p. 4712, 2020.

[56] N. Gramegna, F. Greggio, and F. Bonollo, "Smart factory competitiveness based on real time monitoring and quality predictive model applied to multi-stages production lines," in Advances in Production Management Systems. Towards Smart and Digital Manufacturing, B. Lalic, V. Majstorovic, U. Marjanovic, G. von Cieminski, and D. Romero, Eds., pp. 185-196, Springer International Publishing, Cham, Switzerland, 2020.

[57] M. Sanchez, E. Exposito, and J. Aguilar, "Autonomic computing in manufacturing process coordination in industry 4.0 context," Journal of Industrial Information Integration, vol. 19, p. 100159, 2020.

[58] W. Meng, D. Hongyan, Z. Shiyuan, D. Zhankui, and W. Zige, "The application of the positive semi-definite kernel space for SVM in quality prediction," Recent Advances in Computer Science and Communications, vol. 13, no. 2, pp. 228-233, 2020.

[59] R. H. Fuad, J. M. Nilakantan, and N. Peter, "An integrated approach for line balancing and AGV scheduling towards smart assembly systems," Assembly Automation, vol. 40, no. 2, pp. 219-234, 2020.

[60] S. Khan, M. Farnsworth, R. McWilliam, and J. Erkoyuncu, "On the requirements of digital twin-driven autonomous maintenance," Annual Reviews in Control, vol. 50, pp. 13-28, 2020.

[61] T. Le Grand and R. Deneckere, "COOC: an agile change management method," in Proceedings of the 2019 IEEE 21st Conference on Business Informatics (CBI), pp. 28-37, Moscow, Russia, July 2019.

[62] M. Ebrahimi, A. Baboli, and E. Rother, "A roadmap for evolution of existing production system toward the factory of the future: a case study in automotive industry," in Proceedings of the 2018 IEEE International Conference on Technology Management, Operations and Decisions (ICTMOD), pp. 274-281, Marrakech, Morocco, November 2018.

[63] L. Mazzola, P. Waibel, P. Kaphanke, and M. Klusch, "Smart process optimization and adaptive execution with semantic services in cloud manufacturing," Information, vol. 9, no. 11, pp. 279-307, 2018.

[64] A. Legarretaetxebarria, M. Quartulli, I. Olaizola, and M. Serrano, "Optimal scheduling of manufacturing processes across multiple production lines by polynomial optimization and bagged bounded binary knapsack," International Journal on Interactive Design and Manufacturing (IJIDeM), vol. 11, no. 1, pp. 83-91, 2017.

[65] L. Banjanovic-Mehmedovic and A. Baluković, "PSO optimized fuzzy controller for mobile robot path tracking," in New Technologies, Development and Application III Cham, I. Karabegović, Ed., pp. 413-421, Springer International Publishing, Cham, Switzerland, 2020.

[66] R. Carli, S. Digiesi, M. Dotoli, and F. Facchini, "A control strategy for smart energy charging of warehouse material handling equipment," Procedia Manufacturing, vol. 42, pp. 503-510, 2020. 
[67] M. Kaltenbrunner, M. A. Huka, and M. Gronalt, "Automating production planning and control in pallet manufacturing-a case study," Procedia Manufacturing, vol. 42, pp. 119-124, 2020.

[68] M. R. Islam, J. Al Rafi, and M. S. Hossain, "Operation planning of renewable energy based hybrid system incorporating waste-to-energy (WtE) technologies," in Proceedings of the 2019 International Conference on Sustainable Technologies for Industry 4.0, STI, pp. 1-5, Dhaka, Bangladesh, December 2019.

[69] M. Liu and X. Liu, "Machine scheduling with stochastic release and processing times," IFAC-PapersOnLine, vol. 52, no. 13, pp. 2116-2121, 2019.

[70] H. E. van Staden and R. N. Boute, "The effect of multi-sensor data on condition-based maintenance policies," European Journal of Operational Research, vol. 290, no. 2, pp. 585-600, 2020.

[71] Z. Ma, J. Korsgaard, and B. N. Jorgensen, "Optimization of greenhouse production process: an investigation of energy efficiency potentials," in Proceedings of the 2019 6th International Conference on Dependable Systems and their Applications, DSA, pp. 365-370, Harbin, China, January 2020.

[72] M. Nouiri, D. Trentesaux, and A. Bekrar, "Towards energy efficient scheduling of manufacturing systems through collaboration between cyber physical production and energy systems," Energies, vol. 12, no. 23, p. 4448, 2019.

[73] S. Mantovani, I. L. Presti, L. Cavazzoni, and A. Baldini, "Influence of manufacturing constraints on the topology optimization of an automotive dashboard," Procedia Manufacturing, vol. 11, pp. 1700-1708, 2017.

[74] V. Cardini, M. Eugeni, A. Boschetto et al., "An additive manufacturing redesign of a military aircraft equipment within a logistic 4.0 framework," in Proceedings of the International Astronautical Congress, IAC, Washington, DC, USA, October 2019.

[75] M. Leite, T. Pinto, and C. Alves, "A real-time optimization algorithm for the integrated planning and scheduling problem towards the context of industry 4.0," FME Transactions, vol. 47, no. 4, pp. 775-781, 2019.

[76] T. H. Hsu, L. C. Wang, and P. C. Chu, "Development of a cloud-based advanced planning and scheduling system," Procedia Manufacturing, vol. 17, pp. 427-434, 2018.

[77] T. Drews, P. Molenda, O. Oechsle, and J. Koller, "Manufacturing system optimization with lean methods, manufacturing process objectives and fuzzy logic controller design," Procedia CIRP, vol. 93, pp. 658-663, 2020.

[78] R. Ribeiro, C. Analide, and O. Belo, "Improving productive processes using a process mining approach," in Trends and Advances in Information Systems and Technologies, Á. Rocha, H. Adeli, L. P. Reis, and S. Costanzo, Eds., pp. 736-745, Springer International Publishing, Cham, Switzerland, 2018.

[79] K. Zhang, W. Li, Y. Han, Z. Geng, and C. Chu, "Production capacity identification and analysis using novel multivariate nonlinear regression: application to resource optimization of industrial processes," Journal of Cleaner Production, vol. 282, p. $124469,2020$.

[80] B. A. McCarl, H. Moskowitz, and H. Furtan, "Quadratic programming applications,” Omega, vol. 5, no. 1, pp. 43-55, 1977.

[81] H. Liu, Y. Li, Z. Duan, and C. Chen, "A review on multiobjective optimization framework in wind energy forecasting techniques and applications," Energy Conversion and Management, vol. 224, p. 113324, 2020.
[82] N. V. Sahinidis, "Optimization under uncertainty: state-ofthe-art and opportunities," Computers \& Chemical Engineering, vol. 28, no. 6-7, pp. 971-983, 2004.

[83] C. A. Petri, "Kommunikation mit automaten," Ph. D. Thesis, Institut für Instrumentelle Mathematik, Bonn, Germany, 1962.

[84] F. Friedler, K. Tarján, Y. W. Huang, and L. T. Fan, “Graphtheoretic approach to process synthesis: axioms and theorems," Chemical Engineering Science, vol. 47, no. 8, pp. 1973-1988, 1992.

[85] E. Kondili, C. C. Pantelides, and R. W. H. Sargent, "A general algorithm for short-term scheduling of batch operations-I. MILP formulation," Computers \& Chemical Engineering, vol. 17, no. 2, pp. 211-227, 1993.

[86] M. Liu and X. Liu, "Profit-driven stochastic scheduling considering discounted cash flows under industry 4.0," IFAC-PapersOnLine, vol. 52, no. 13, pp. 2122-2127, 2019.

[87] R. B. Kuriakose and H. J. Vermaak, "Optimization of a real time web enabled mixed model stochastic assembly line to reduce production time," Communications in Computer and Information Science, vol. 1075, pp. 39-50, 2019.

[88] C. Müller, M. Grunewald, and T. S. Spengler, "Redundant configuration of robotic assembly lines with stochastic failures," International Journal of Production Research, vol. 56, no. 10, pp. 3662-3682, 2018.

[89] P. Marangé, D. Lemoine, A. Aubry et al., "Coupling robust optimization and model-checking techniques for robust scheduling in the context of industry 4.0," in Scheduling in Industry 4.0 and Cloud Manufacturing, B. Sokolov, D. Ivanov, and A. Dolgui, Eds., pp. 103-124, Springer International Publishing, Cham, Switzerland, 2020.

[90] Q. Zaman and A. König, "Self-x integrated sensor circuits immune to measurement noise in the presence of input perturbation by using robust optimization," Technisches Messen, vol. 86, no. 1, pp. S107-S111, 2019.

[91] C. Hu, X. Liu, J. Lu, and C.-H. Wang, "Distributionally robust optimization for power trading of waste-to-energy plants under uncertainty," Applied Energy, vol. 276, p. 115509, 2020.

[92] J. Pierezan, G. Maidl, E. Massashi Yamao, L. dos Santos Coelho, and V. Cocco Mariani, "Cultural coyote optimization algorithm applied to a heavy duty gas turbine operation," Energy Conversion and Management, vol. 199, p. 111932, 2019.

[93] J. Del Ser, E. Osaba, D. Molina et al., "Bio-inspired computation: where we stand and what's next," Swarm and Evolutionary Computation, vol. 48, pp. 220-250, 2019.

[94] J. L. S. De Silva, D. B. De Mesquita, H. S. Moreira et al., "Industry 4.0 approach aligned with the challenges of gridconnected photovoltaic systems," in Proceedings of the 2019 IEEE PES Conference on Innovative Smart Grid Technologies, ISGT Latin America, Gramado, Brazil, September 2019.

[95] C. Kim and H. Oh, "Simulation-based sensor network optimal design for detecting fracture in pipeline systems," in Proceedings of SPIE-the International Society for Optical Engineering, Volume 10973, Denver, CO, USA, March 2019.

[96] M. Liu, Z. Liu, X. Liu, and F. Chu, "Entropy-based bi-objective disassembly line balancing problem," in Proceedings of the 2019 International Conference on Industrial Engineering and Systems Management, IESM, Shanghai, China, September 2019.

[97] M. P. Marcos, J. L. Pitarch, and C. de Prada, "Decision support system for a heat-recovery section with equipment 
degradation," Decision Support Systems, vol. 137, p. 113380, 2020.

[98] D. Bechtsis, N. Tsolakis, M. Vouzas, and D. Vlachos, "Industry 4.0: sustainable material handling processes in industrial environments," Computer Aided Chemical Engineering, vol. 40, pp. 2281-2286, 2017.

[99] A. Pichler, S. Poledna, and S. Thurner, "Systemic risk-efficient asset allocations: minimization of systemic risk as a network optimization problem," Journal of Financial Stability, p. 100809, 2020.

[100] Y. Sun, N. V. Sahinidis, A. Sundaram, and M.-S. Cheon, "Derivative-free optimization for chemical product design," Current Opinion in Chemical Engineering, vol. 27, pp. 98106, 2020.

[101] H. Gao, A. Waechter, I. A. Konstantinov, S. G. Arturo, and L. J. Broadbelt, "Application and comparison of derivativefree optimization algorithms to control and optimize free radical polymerization simulated using the kinetic Monte Carlo method," Computers \& Chemical Engineering, vol. 108, pp. 268-275, 2018.

[102] I. Negrellos-Ortiz, A. Flores-Tlacuahuac, and M. A. Gutiérrez-Limón, "Dynamic optimization of a cryogenic air separation unit using a derivative-free optimization approach," Computers \& Chemical Engineering, vol. 109, pp. 1-8, 2018.

[103] L. Benhamou, V. Giard, M. Khouloud, P. Fenies, and F. Fontane, "Reverse blending: an economically efficient approach to the challenge of fertilizer mass customization," International Journal of Production Economics, vol. 226, p. $107603,2020$.

[104] J. Hong, N. Van Duc Long, G. R. Harvianto, J. Haider, and M. Lee, "Design and optimization of multi-effect-evaporation-assisted distillation configuration for recovery of 2,3butanediol from fermentation broth," Chemical Engineering and Processing-Process Intensification, vol. 136, pp. 107-115, 2019.

[105] Y. Jiang, E. Liese, S. E. Zitney, and D. Bhattacharyya, "Optimal design of microtube recuperators for an indirect supercritical carbon dioxide recompression closed Brayton cycle," Applied Energy, vol. 216, pp. 634-648, 2018.

[106] D. Erkin, E. Dugundji, G. Koole, J. Gromicho, and R. van der Mei, "Buffering locations in retail deliveries," Procedia Computer Science, vol. 151, pp. 116-123, 2019.

[107] S. M. Hassan, M. Azab, and A. Mokhtar, "Smart concrete transportation in semi-automated construction sites," in Proceedings of the 2019 IEEE 10th Annual Information Technology, Electronics and Mobile Communication Conference, IEMCON, pp. 661-667, Vancouver, Canada, October 2019.

[108] D. A. Chekired, L. Khoukhi, and H. T. Mouftah, "Industrial IoT data scheduling based on hierarchical fog computing: a key for enabling smart factory," IEEE Transactions on Industrial Informatics, vol. 14, no. 10, pp. 4590-4602, 2018.

[109] J. Jayakumar, J. Kandasamy, K. E. K. Vimal, and S. Hasibuan, "Modelling of sharing networks in the circular economy," Journal of Modelling in Management, vol. 15, no. 2, pp. 407-440, 2020.

[110] L. Bukata, P. Sucha, Z. Hanzalek, and P. Burget, "Energy optimization of robotic cells," IEEE Transactions on Industrial Informatics, vol. 13, no. 1, pp. 92-102, 2017.

[111] Z. A. Çil, Z. Li, S. Mete, and E. Özceylan, "Mathematical model and bee algorithms for mixed-model assembly line balancing problem with physical human-robot collaboration," Applied Soft Computing Journal, vol. 93, p. 106394, 2020.

[112] B. Mihoubi, B. Bouzouia, and M. Gaham, "Reactive scheduling approach for solving a realistic flexible job shop scheduling problem," International Journal of Production Research, pp. 1-19, 2020.

[113] V. P. Zhalnin, A. S. Zakharova, D. A. Uzenkov, A. I. Vlasov, A. I. Krivoshein, and S. S. Filin, "Configuration-making algorithm for the smart machine controller based on the internet of things concept," International Review of Electrical Engineering (IREE), vol. 14, no. 5, pp. 375-384, 2019.

[114] I. Maganha, C. Silva, N. Klement, A. B. dit Eynaud, L. Durville, and S. Moniz, "Hybrid optimisation approach for sequencing and assignment decision-making in reconfigurable assembly lines," IFAC-PapersOnLine, vol. 52, no. 13, pp. 1367-1372, 2019.

[115] P. Zhang, C. Wang, Z. Qin, and H. Cao, "A multidomain virtual network embedding algorithm based on multiobjective optimization for internet of drones architecture in industry 4.0," Software-Practice and Experience, pp. 1-19, 2020.

[116] G. H. A. Medeiros, Q. Cao, C. Zanni-Merk, and A. Samet, "Manufacturing as a service in industry 4.0: a multi-objective optimization approach," in Intelligent Decision Technologies, I. Czarnowski, R. J. Howlett, and L. C. Jain, Eds., Springer, Singapore, pp. 37-47, 2020

[117] M. Afrin, J. Jin, A. Rahman, Y.-C. Tian, and A. Kulkarni, "Multi-objective resource allocation for edge cloud based robotic workflow in smart factory," Future Generation Computer Systems, vol. 97, pp. 119-130, 2019.

[118] P. Davidsson, J. A. Persson, and J. Holmgren, "On the integration of agent-based and mathematical optimization techniques," in Agent and Multi-Agent Systems: Technologies and Applications, N. T. Nguyen, A. Grzech, R. J. Howlett, and L. C. Jain, Eds., pp. 1-10, Springer, Berlin, Germany, 2007.

[119] H.-P. Wiendahl and P. Scholtissek, "Management and control of complexity in manufacturing," CIRP Annals, vol. 43, no. 2, pp. 533-540, 1994.

[120] C. C. Bozarth, D. P. Warsing, B. B. Flynn, and E. J. Flynn, "The impact of supply chain complexity on manufacturing plant performance," Journal of Operations Management, vol. 27, no. 1, pp. 78-93, 2009.

[121] A. V. Deshmukh, J. J. Talavage, and M. M. Barash, "Complexity in manufacturing systems, part 1: analysis of static complexity," IIE Transactions, vol. 30, no. 7, pp. 645-655, 1998.

[122] G. Ausiello, A. Marchetti-Spaccamela, P. Crescenzi, G. Gambosi, M. Protasi, and V. Kann, Complexity and Approximation-Combinatorial Optimization Problems and their Approximability Properties, Springer, Berlin, Germany, 1999.

[123] M. Ghaleb, H. Zolfagharinia, and S. Taghipour, "Real-time production scheduling in the industry-4.0 context: addressing uncertainties in job arrivals and machine breakdowns," Computers \& Operations Research, vol. 123, p. 105031, 2020.

[124] H. ElMaraghy, A. Azab, G. Schuh, and C. Pulz, "Managing variations in products, processes and manufacturing systems," CIRP Annals, vol. 58, no. 1, pp. 441-446, 2009.

[125] Y. Koren, The Global Manufacturing Revolution: ProductProcess-Business Integration and Reconfigurable Systems, John Wiley \& Sons, Hoboken, NJ, USA, 2010.

[126] D. A. Rossit, F. Tohmé, and M. Frutos, "Production planning and scheduling in cyber-physical production systems: a 
review," International Journal of Computer Integrated Manufacturing, vol. 32, no. 4-5, pp. 385-395, 2019.

[127] F. Sahin, A. Narayanan, and E. P. Robinson, "Rolling horizon planning in supply chains: review, implications and directions for future research," International Journal of Production Research, vol. 51, no. 18, pp. 5413-5436, 2013.

[128] C. Cimino, E. Negri, and L. Fumagalli, "Review of digital twin applications in manufacturing," Computers in Industry, vol. 113, p. 103130, 2019.

[129] J. Mertens, M. Challenger, K. Vanherpen, and J. Denil, "Towards real-time cyber-physical systems instrumentation for creating digital twins," in Proceedings of the 2020 Spring Simulation Conference (SpringSim), pp. 1-12, IEEE, Fairfax, VA, USA, May 2020.

[130] G. Zhou, C. Zhang, Z. Li, K. Ding, and C. Wang, "Knowledge-driven digital twin manufacturing cell towards intelligent manufacturing," International Journal of Production Research, vol. 58, no. 4, pp. 1034-1051, 2020.

[131] F. Caputo, A. Greco, M. Fera, and R. Macchiaroli, "Digital twins to enhance the integration of ergonomics in the workplace design," International Journal of Industrial Ergonomics, vol. 71, pp. 20-31, 2019.

[132] T. Gabor, L. Belzner, M. Kiermeier, M. T. Beck, and A. Neitz, "A simulation-based architecture for smart cyber-physical systems," in Proceedings of the 2016 IEEE International Conference on Autonomic Computing (ICAC), pp. 374-379, IEEE, Wurzburg, Germany, July 2016.

[133] J. De Tommaso, F. Rossi, N. Moradi, C. Pirola, G. S. Patience, and F. Galli, "Experimental methods in chemical engineering: process simulation," The Canadian Journal of Chemical Engineering, vol. 98, no. 11, pp. 2301-2320, 2020.

[134] Y. Chen, O. Yang, C. Sampat, P. Bhalode, R. Ramachandran, and M. Ierapetritou, "Digital twins in pharmaceutical and biopharmaceutical manufacturing: a literature review," Processes, vol. 8, no. 9, p. 1088, 2020.

[135] K. Židek, J. Pitel', M. Adámek, P. Lazorík, and A. Hošovskỳ, "Digital twin of experimental smart manufacturing assembly system for industry 4.0 concept," Sustainability, vol. 12, no. 9, p. $3658,2020$.

[136] K. Y. H. Lim, P. Zheng, C.-H. Chen, and L. Huang, "A digital twin-enhanced system for engineering product family design and optimization," Journal of Manufacturing Systems, vol. 57, pp. 82-93, 2020.

[137] R. Batres, "Ontologies in process systems engineering," Chemie Ingenieur Technik, vol. 89, no. 11, pp. 1421-1431, 2017.

[138] J. Wan, B. Yin, D. Li, A. Celesti, F. Tao, and Q. Hua, “An ontology-based resource reconfiguration method for manufacturing cyber-physical systems," IEEE/ASME Transactions on Mechatronics, vol. 23, no. 6, pp. 2537-2546, 2018.

[139] H. Tang, D. Li, S. Wang, and Z. Dong, "CASOA: an architecture for agent-based manufacturing system in the context of industry 4.0," IEEE Access, vol. 6, pp. 1274612754, 2017

[140] J. Pękala, "Data transformation using custom class generator as part of systems integration in manufacturing company," in Proceedings of the International Conference on Computer Networks, pp. 397-409, Brunów, Poland, June 2016.

[141] U. Kannengiesser, M. Neubauer, and R. Heininger, "Integrating business processes and manufacturing operations based on S-BPM and B2MML," in Proceedings of the 8th International Conference on Subject-Oriented Business Process Management, pp. 1-10, Erlangen, Germany, April 2016.
[142] I. Harjunkoski, M. Hollender, R. Bauer, J. Doppelhamer, and S. Subbiah, "An easy-to-use and flexible scheduling component," ABB Review, vol. 3, pp. 92-97, 2017.

[143] M. Fechter, C. Seeber, and S. Chen, "Integrated process planning and resource allocation for collaborative robot workplace design," Procedia CIRP, vol. 72, pp. 39-44, 2018.

[144] G. Thiele, N. Khorsandi, and J. Krüger, "Energy efficiency optimization using AutomationML modeling and an EnPI methodology," in Proceedings of the 2019 24th IEEE International Conference on Emerging Technologies and Factory Automation (ETFA), pp. 1218-1221, IEEE, Zaragoza, Spain, September 2019.

[145] M. Fechter and A. Neb, "From 3D product data to hybrid assembly workplace generation using the AutomationML exchange file format," Procedia CIRP, vol. 81, pp. 57-62, 2019.

[146] P. Novák, F. J. Ekaputra, and S. Biffl, "Generation of simulation models in MATLAB-simulink based on AutomationML plant description," IFAC-PapersOnLine, vol. 50, no. 1, pp. 7613-7620, 2017.

[147] A. Mazak, A. Lüder, S. Wolny et al., "Model-based generation of run-time data collection systems exploiting AutomationML," at-Automatisierungstechnik, vol. 66, no. 10, pp. 819-833, 2018. 